[Review]

\title{
层状双金属氢氧化物的剥离方法及其应用
}

\author{
聂宏寒 侯万国 ${ }^{*}$ \\ (山东大学胶体与界面化学教育部重点实验室, 济南 250100)
}

\begin{abstract}
摘要: 层状双金属氢氧化物(LDHs)是由带结构正电荷的片层和层间阴离子有序组装而成的层状无机化合物, 近期其剥离研究受到关注. 剥离后的 LDHs 纳米片可被看做 “无机高分子”, 具有纳米尺度的开放结构, 既可作 为理论研究模型, 又可作为新型基元组装功能复合纳米结构或材料, 具有显著的应用潜力. 本文对 LDHs 的剥 离方法、剥离产物的表征方法及其应用研究现状进行了综述, 并对今后的研究方向进行了展望.
\end{abstract}

关键词：层状双金属氢氧化物; 类水滑石; 剥离; 甲酰胺

中图分类号: 0648

\section{Methods and Applications for Delamination of Layered Double Hydroxides}

\author{
NIE Hong-Qian HOU Wan-Guo* \\ (Key Laboratory for Colloid and Interface Chemistry of the Ministry of Education, Shandong University, Jinan 250100, P. R. China)
}

\begin{abstract}
Layered double hydroxides (LDHs) are a class of layered inorganic materials that consist of structurally positively charged layers and exchangeable anions in the interlayer gallery for charge balance. The delamination of LDHs has attracted much attention in the last decade because it is an effective way for exposing the inner surfaces of the host layers. Delaminated nanosheets may be referred to as "macromolecules", and they have opened nanostructures. They can be used as an ideal model system and as building blocks for various multilayer ultrathin films and functional nanocomposites. In this article, we outline the progress made regarding the delamination of LDHs and pose future challenges.
\end{abstract}

Key Words: Layered double hydroxide; Hydrotalcite-like compound; Delamination; Formamide

\section{1 引言}

层状双金属氢氧化物(简称 LDHs) 又称类水滑 石(简称 HTlc), 是由两种或两种以上金属元素组成 的具有水滑石层状晶体结构的氢氧化物. LDHs 具 有层状结构, 层片带结构正电荷, 层间存在可交换 阴离子, 其晶体结构如图 1 所示. ${ }^{1} \mathrm{LDHs}$ 的基本构造 单元是金属-(氢)氧八面体, 八面体中心是金属离 子, 六个顶角是 $\mathrm{OH}^{-}$; 相邻八面体间靠共用边相互联 结形成二维延伸的配位八面体结构层, 即单元晶
层; 单元晶层面-面堆叠形成晶体颗粒. LDHs 的化学 组成通式为 $\left[\mathrm{M}_{1-x}^{\mathrm{II}} \mathrm{M}_{x}^{\mathrm{III}}(\mathrm{OH})_{2}\right]^{x+}\left[\mathrm{A}_{x / n}^{n-}\right]^{x-} \cdot m \mathrm{H}_{2} \mathrm{O}$, 式中, $\mathrm{M}^{\mathrm{II}}$ 指二价金属阳离子, 如 $\mathrm{Mg}^{2+} 、 \mathrm{Mn}^{2+} 、 \mathrm{Fe}^{2+} 、 \mathrm{Co}^{2+}$ 、 $\mathrm{Zn}^{2+} 、 \mathrm{Ca}^{2+}$ 等; $\mathrm{M}^{\mathrm{III}}$ 指三价金属阳离子, 如 $\mathrm{Al}^{3+} 、 \mathrm{Cr}^{3+}$ 、 $\mathrm{Mn}^{3+} 、 \mathrm{Fe}^{3+} 、 \mathrm{Co}^{3+}$ 等; $\mathrm{A}^{n-}$ 指价数为 $n$ 的阴离子, 如 $\mathrm{Cl}^{-}$、 $\mathrm{OH}^{-} 、 \mathrm{NO}_{3}^{-} 、 \mathrm{CO}_{3}^{2-} 、 \mathrm{SO}_{4}^{2-}$ 以及有机阴离子等; $x$ 是每摩 尔 $\mathrm{LDHs}$ 中 $\mathrm{M}^{\mathrm{III}}$ 的摩尔数; $m$ 是每摩尔 $\mathrm{LDHs}$ 中结晶 水的摩尔数.二价和三价金属离子的不同配对组成 了种类繁多的具有不同性能的层状双金属氢氧化

Received: February 23, 2011; Revised: May 3, 2011; Published on Web: June 23, 2011.

*Corresponding author. Email: wghou@sdu.edu.cn; Tel: +86-531-88365460.

The project was supported by the Natural Science Foundation of Shandong Province, China (Z2008B08, 2009ZRB01722) and Taishan Scholar Foundation of Shandong Province, China (ts20070713).

山东省自然科学基金(Z2008B08, 2009ZRB01722)和山东省泰山学者基金(ts20070713)资助项目

(C) Editorial office of Acta Physico-Chimica Sinica 

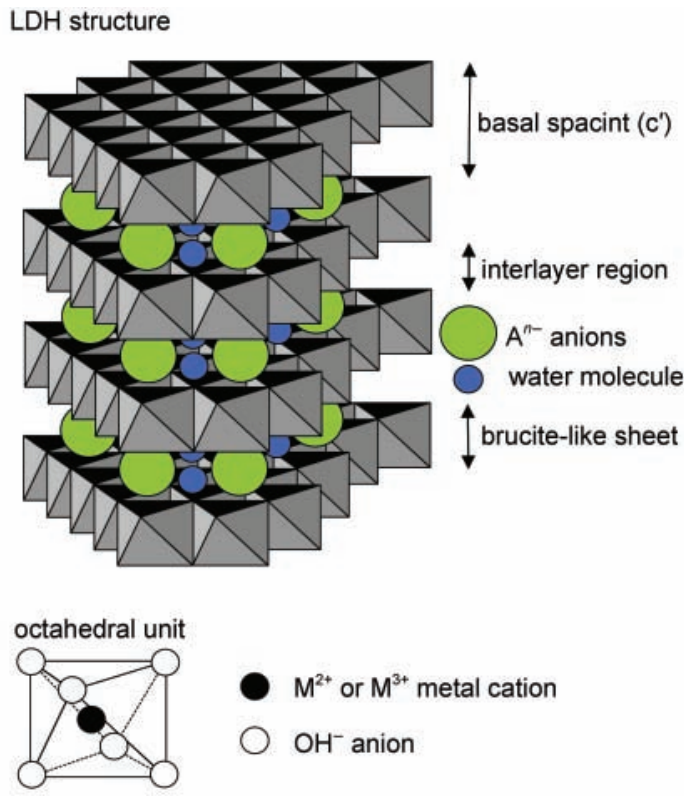

图 1 LDHs 的晶体结构示意图 ${ }^{1}$

Fig.1 Schematic crystal structure of LDHs ${ }^{1}$ LDHs: layered double hydroxides

物. ${ }^{2-5}$ 这些独特的结构和性能使其在催化、 ${ }^{6-11}$ 离子 交换和吸附、年-28 电化学和磁学、年-32 光化学、、 药载体 ${ }^{37-50}$ 等众多领域具有广泛的应用前景.

近十几年来, LDHs 的剥离受到广泛关注. ${ }^{51-87}$ 在 一定条件下, LDHs 颗粒经剥离可形成分散状态的 纳米尺度单元晶片. 这些纳米片带正电, 具二维属 性, 既可作为相关基础研究的模型, 也可作为新型 基元通过自组装构建新型纳米复合结构或材料, 具 有广阔的应用前景. 本文综述了LDHs 的剥离、表征 及其应用方面的研究进展.

\section{2 层状双金属氢氧化物的剥离方法}

LDHs 层片带高密度的正电荷, 与层间阴离子 存在较强的静电作用, 因而其剥离难度较大. 至今, 已报道的剥离方法可根据剥离溶剂的不同大体分 为三类: 短链醇中的剥离、甲酰胺中的剥离和水中 的剥离.

\section{1 短链醇中的剥离}

在 LDHs 的剥离研究中最先使用的溶剂为短链 醇. 51 ,52 先将阴离子表面活性剂插入 LDHs 的层间, 对 其层间进行修饰, 撑大其层间距, 再在短链醇中热 处理, 有可能实现 LDHs 的剥离. 研究表明, 能否实 现 LDHs 的剥离与阴离子表面活性剂、短链醇和 LDHs 的种类有关, 也与实验条件有关.

Adachi-Pagano 等 ${ }^{51}$ 于 2000 年报道了表面活性 剂十二烷基硫酸钠(SDS)插层的 $\mathrm{Zn}_{2} \mathrm{Al}-\mathrm{Cl} \mathrm{LDHs}$ (简
记为 $\mathrm{Zn}_{2} \mathrm{Al}-\mathrm{SDS} \mathrm{LDHs}$ ) 在丁醇中的剥离. 将 $\mathrm{Zn}_{2} \mathrm{Al}-$ SDS LDHs 置于丁醇中在 $120^{\circ} \mathrm{C}$ 条件下回流 $12 \mathrm{~h}$, 得到透明的分散体系, 表明 LDHs 被剥离, 其剥离的 最高浓度为 $1.5 \mathrm{~g} \cdot \mathrm{L}^{-1}$. 剥离后的胶态分散体在室温 下可稳定存在至少 8 个月. 他们 ${ }^{51,52}$ 还考察了其它溶 剂的剥离效果, 发现以水、甲醇、乙醇、异丙醇及己 烷为溶剂时, 在同样条件下剥离得到的悬浮液均不 稳定, 静置几小时后, 大部分颗粒均发生沉降, 而以 戊醇和己醇作溶剂时剥离效果与丁醇作溶剂类似, 可成功剥离. 他们 ${ }^{51,52}$ 认为 LDHs 成功剥离的关键条 件有两个: 其一是 LDHs 的水化状态, 只有室温真空 干燥一天的样品才可以剥离, 而新制备湿样或者是 $80^{\circ} \mathrm{C}$ 条件下真空干燥的样品都不能剥离; 其二是 LDHs 层间水能否被短链醇取代, 沸点比水高的丁 醇在回流条件下可迅速取代 LDHs 的层间水, 因而 利于剥离. 将剥离产物进行重新组装, 发现重组装 产物的性质与组装方法有关: 采用冷冻干燥法或置 于含相应阴离子的盐溶液中重组装法, 可得到有序 排列相, 而通过蒸发溶剂法则得到无定形相.

Singh 等 ${ }^{53}$ 研究了四种表面活性剂插层修饰后 的锂铝型 $\mathrm{LDHs}\left(\left[\mathrm{LiAl}_{2}(\mathrm{OH})_{6}\right] \mathrm{Cl} \cdot n \mathrm{H}_{2} \mathrm{O}\right)$ 以丁醇为溶 剂在 $120{ }^{\circ} \mathrm{C}$ 下回流 $16 \mathrm{~h}$ 的剥离效果, 发现辛基硫酸 钠(SOS)和十二烷基硫酸钠(SDS)插层的 LDHs 不能 剥离, 而辛基苯磺酸钠(SOBS)和十二烷基苯磺酸钠 (SDBS) 插层的 LDHs 成功剥离. 他们认为层板剥离 成功与否不仅与前体的水化程度有关, 还与预插入 层间的表面活性剂的链长和头基大小有关, 体积较 大的苯磺酸头基能够使剥离产物稳定, 而体积较小 的硫酸根则不能.

Venugopal 等 ${ }^{4}$ 研究了 SDS 和 SDBS 插层后的镁 铝、镍铝或锌铝氯离子或硝酸根 LDHs, 在不同溶剂 (丁醇、己醇、戊醇、癸醇、已烷和水)中和不同反应条 件下的剥离-重组装行为, 考察了剥离效率(剥离浓 度)和剥离产物的稳定性. 采用的剥离条件分别为: 室温(RT)下摚拌 $48 \mathrm{~h} 、 120^{\circ} \mathrm{C}$ 下搅拌 $4 \mathrm{~h}$ 和 $70^{\circ} \mathrm{C}$ 超 声 $2 \mathrm{~h}$. 不同条件下在丁醇中的剥离浓度 $\left(\mathrm{mmol} \cdot \mathrm{L}^{-1}\right)$ 和剥离产物质量沉降一半时所需时间 $\left(t_{1 / 2}\right)$ 见表 1 . 从 表 $1^{54}$ 结果作者得到如下结论: (1) 从剥离条件看, $120^{\circ} \mathrm{C}$ 下搅拌 $4 \mathrm{~h}$ 或 $70^{\circ} \mathrm{C}$ 超声 $2 \mathrm{~h}$ 可剥离的 $\mathrm{LDHs}$ 浓度较高, 且得到的胶态分散体稳定性也较高; (2) 从类水滑石的金属离子组成看, 金属元素的原子序 数越低的 LDHs 剥离浓度越高, 但剥离后胶态分散 体的稳定性无太大差别; (3) 从金属离子摩尔比看, 
表 1 不同条件下 LDHs 在丁醇中剥离的浓度 $\left(c_{\mathrm{LDH}}\right)$ 及其 胶态分散体的 $\boldsymbol{t}_{1 / 2}{ }^{54}$

Table 1 Concentration of LDHs delaminated in 1-butanol under different conditions and $t_{1 / 2}$ of the colloidal dispersions ${ }^{54}$

\begin{tabular}{|c|c|c|c|c|c|}
\hline \multirow[b]{2}{*}{ LDHs } & \multicolumn{3}{|c|}{$c_{\mathrm{LDH}} /\left(\mathrm{mmol} \cdot \mathrm{L}^{-1}\right)$} & \multicolumn{2}{|r|}{$t_{1 / 2} / \mathrm{d}$} \\
\hline & $\begin{array}{c}\text { RT } \\
\text { stirring }\end{array}$ & $\begin{array}{l}120{ }^{\circ} \mathrm{C} \\
\text { stirring }\end{array}$ & sonication & $\begin{array}{c}\text { RT } \\
\text { stirring }\end{array}$ & $\begin{array}{c}120^{\circ} \mathrm{C} \text { stirring/ } \\
\text { sonication }\end{array}$ \\
\hline $\mathrm{Mg}_{3} \mathrm{Al}-\mathrm{SDS}$ & 2.3 & 2.6 & 2.6 & 2 & 5 \\
\hline $\mathrm{Mg}_{2} \mathrm{Al}-\mathrm{SDS}$ & 1.8 & 2.0 & 2.3 & 3 & 7 \\
\hline $\mathrm{Mg}_{2} \mathrm{Al}-\mathrm{SDBS}$ & 1.8 & 1.8 & 2.3 & 3 & $>7$ \\
\hline $\mathrm{Ni}_{2} \mathrm{Al}-\mathrm{SDS}$ & 1.6 & 1.6 & 1.8 & & 4 \\
\hline $\mathrm{Zn}_{2} \mathrm{Al}-\mathrm{SDS}$ & 1.3 & 1.3 & 1.5 & 2 & 4 \\
\hline $\mathrm{Zn}_{2} \mathrm{Al}-\mathrm{SDBS}$ & 1.2 & 1.7 & 1.7 & $>7$ & $>7$ \\
\hline
\end{tabular}

RT: room temperature; solvent: 1-butanol; SDS: sodium lauryl sulfate; SDBS: sodium dodecylbenzene solfonate.

$\mathrm{M}^{\mathrm{II}} / \mathrm{M}^{\mathrm{III}}$ 比值较低的 LDHs 剥离稳定性较好, 例如 $\mathrm{Mg}_{2} \mathrm{Al}-\mathrm{SDS} \mathrm{LDH}$ 的剥离胶态分散体稳定性比 $\mathrm{Mg}_{3} \mathrm{Al}$-SDS LDH 的高, 可能是前者具有更高的层板 电荷密度, 可插入表面活性剂的量更多, 层间亲油 性更强所致; (4) 从插入的表面活性剂看, 其链结构 影响剥离效果, 如 $\mathrm{Mg}_{2} \mathrm{Al}-\mathrm{SDS} \mathrm{LDH}$ 与 $\mathrm{Mg}_{2} \mathrm{Al}-\mathrm{SDBS}$ LDH 相比, 后者剥离后的分散体系更稳定, 这是由 于 SDBS 链结构中苯基的存在使层板间具有更高的 亲油性. 表 2 是 $\mathrm{Mg}_{2} \mathrm{Al}-\mathrm{SDBS} \mathrm{LDH}$ 在不同溶剂中 $70{ }^{\circ} \mathrm{C}$ 超声 $2 \mathrm{~h}$ 的剥离效果 ${ }^{54}$. 结果表明, 最适宜剥离 的溶剂为有机醇类, 如丁醇、已醇、戊醇和癸醇; 在 非极性溶剂己烷中则极少量剥离且剥离分散液不 稳定; 在水中则完全不可剥离. 他们通过不同的重 组装方法对剥离产物进行了重组装, 如蒸发溶剂 法、沉淀法和将稀释的胶态分散体滴在玻璃片上使 其蒸发干燥的方法, 发现重组装产物的红外光谱与 前体基本一致, XRD 图中存在 LDHs 特征衍射峰, 但 峰变宽, 表明其层间距有所增大, 认为是由重组装 后层间醇分子的未完全移除或重组过程中的无序 堆积所致.

以上所述, 先将阴离子型表面活性剂插入 LDHs 层间, 扩大其层间距, 增强其层间亲油性, 进

表 $2 \quad \mathrm{Mg}_{2} \mathrm{Al}-\mathrm{SDBS}$ LDH 在不同溶剂中 $70{ }^{\circ} \mathrm{C}$ 超声 $2 \mathrm{~h}$ 后的剥离浓度及胶态分散体的 $\boldsymbol{t}_{1 / 2}{ }^{54}$

Table 2 Concentration of $\mathrm{Mg}_{2} \mathrm{Al}-\mathrm{SDBS} \mathrm{LDH}$ delaminated in different solvents by sonications for $2 \mathrm{~h}$ at $70^{\circ} \mathrm{C}$ and $t_{1 / 2}$ of the colloidal dispersions ${ }^{54}$

1-butanol 1-hexanol 1-octanol 1-decanol $n$-hexane $\mathrm{H}_{2} \mathrm{O}$

\begin{tabular}{|c|c|c|c|c|c|c|}
\hline$\frac{c_{\text {solvent }}}{\left(\mathrm{mmol} \cdot \mathrm{L}^{-1}\right)}$ & 2.3 & 1.9 & 1.9 & 1.8 & 0.5 & 0 \\
\hline$t_{12} / \mathrm{d}$ & $>7$ & - & - & 3 & $1 / 6$ & - \\
\hline
\end{tabular}

而在短链醇溶剂中热处理, 虽然可以实现 LDHs 层 板的剥离, 但存在剥离条件复杂(需要加热回流或者 超声)、反应时间较长及剥离浓度较低等缺点.

\section{2 甲酰胺中的剥离}

Hibino 等 ${ }^{55}$ 于 2001 年首次报道了 LDHs 在甲酰 胺溶剂中室温下的剥离. 将预先经甘氨酸(Gly)插层 的镁铝型 LDHs(MgAl-Gly LDHs)在甲酰胺中室温 下搅拌数分钟, 发现可形成透明的胶态分散体, 表 明 $\mathrm{LDHs}$ 发生剥离, 最高剥离浓度为 $3 \mathrm{~g} \cdot \mathrm{L}^{-1}$. 他们认 为, 甘氨酸与甲酰胺间较强的氢键作用是剥离过程 的驱动力, 大量的甲酰胺因氢键作用进入 LDHs 层 间, 将层间距撑大而最终导致层板剥离. 此方法简 便、快捷, 不需加热、回流等条件. 将剥离的胶态分 散体重复多次滴到载玻片上, $25^{\circ} \mathrm{C}$ 干燥后发现可重 组装成 LDHs 层状结构. 随后, Hibino ${ }^{56}$ 扩展了插入 层间的氨基酸的种类(包括亮氨酸等 14 种氨基酸)及 类水滑石的金属元素种类 $(\mathrm{Co}-\mathrm{Al} 、 \mathrm{Zn}-\mathrm{Al}$ 和 $\mathrm{Ni}-\mathrm{Al}$ 型 类水滑石), 发现氨基酸的插入量对剥离效果影响很 大. 插入氨基酸的负电荷数与层板正电荷数之比控 制在 $15 \%-20 \%$ 以下为宜, 如果氨基酸插入量过高, 因氨基酸分子之间形成氢键网络反而不利于层板 的剥离; 但插入氨基酸的负电荷数与层板正电荷数 之比却没有最低限制值, 如精氨酸和谷氨酸在其比 值小于 $1 \%$ 的条件下仍可以完全剥离. 另外发现所 研究 LDHs 的金属元素种类不影响其剥离效果, 如 甘氨酸插层的 Co-Al、 $\mathrm{Zn}-\mathrm{Al}$ 和 Ni-Al 型 LDHs 均可 以剥离. 为证实氢键作用是剥离的驱动力, Hibino ${ }^{56}$ 做了三个验证实验. 第一个实验是选取水、甲醇等 一系列溶剂, 分别与剥离的 MgAl-Gly LDHs 胶态分 散体以体积比 1:1 混合, 发现得到的体系均很稳定; 但在 $1500 \mathrm{r} \cdot \mathrm{min}^{-1}$ 下离心 $10 \mathrm{~min}$ 后, 发现以甲醇、乙 醇、丙酮或碳酸丙烯酯配制的体系出现了胶状沉淀 物, 而以水和 $N$-甲基甲酰胺配制的体系未出现沉淀 物. 他们认为, 稳定性与溶剂的相对介电常数有关. 相对介电常数越低, 颗粒之间的库仑力越小, 越容 易产生沉淀. 与甲酰胺相比, 甲醇、乙醇、丙酮或碳 酸丙烯酯的相对介电常数 $(D=20-65)$ 均远低于甲酰 胺的 $D$ 值 $(D=110)$, 而水和 $N$-甲基甲酰胺的 $D$ 值 $(D=$ 80-180) 则高于甲酰胺的 $D$ 值. 由此得出在甲酰胺 中剥离后的 LDHs 层片之间靠静电力稳定的结论. 第二个实验是将 MgAl-Gly LDHs 加入到含有不同 浓度 $\left(0.001-0.5 \mathrm{~mol} \cdot \mathrm{L}^{-1}\right)$ 氯化钠的甲酰胺中, 发现当 氯化钠浓度大于 $0.1 \mathrm{~mol} \cdot \mathrm{L}^{-1}$ 时, 大部分 $\mathrm{LDHs}$ 不能 
剥离且迅速产生沉淀, 表明盐的存在扰乱了 LDHs 与甲酰胺之间的溶剂化作用, 而溶剂化作用通常是 由静电相互作用 (如偶极-偶极引力和氢键)引起的. 第三个实验是选取水、甲醇等一系列极性溶剂, 考 察溶剂的剥离能力, 发现甲酰胺是唯一能剥离 LDHs 的溶剂. 氢键是分子间一种特别强的偶极-偶 极引力作用, 其中氢原子被共价键键合到强负电性 元素如氧和氮上. 甲酰胺分子中含有一个氧原子和 一个氮原子, 其强负电性元素与其他元素之比在所 测试的溶剂中最高, 因此其形成氢键的能力最强. 鉴于以上实验结果, Hibino ${ }^{56}$ 认为氢键作用是 MgAl-Gly LDHs 在甲酰胺中剥离的驱动力.

LDHs 在甲酰胺中的剥离逐渐受到关注, 人们 开始探索 LDHs 金属组成和剥离条件等对剥离效果 的影响. Guo 等 ${ }^{57}$ 将 SDS 插层的 $\mathrm{CdCr}-\mathrm{NO}_{3} \mathrm{LDHs}$ 和 $\mathrm{ZnCdCr}-\mathrm{NO}_{3} \mathrm{LDHs}_{\mathrm{s}}$ 在甲酰胺中室温搅拌三天, 得到 透明胶态分散体, 表明 LDHs 被剥离, 剥离浓度为 3 $\mathrm{g} \cdot \mathrm{L}^{-1}$, 剥离体系可稳定存在 6 个月. $\mathrm{Wu}$ 等 ${ }^{58}$ 发现在 甲酰胺中采用超声辅助处理, LDHs 不经预插层即 可剥离, 且剥离浓度明显提高. 例如, $\mathrm{Mg}_{3} \mathrm{Al}-\mathrm{NO}_{3}$ LDHs 在甲酰胺中进行超声处理即可完全剥离, 其 剥离浓度可达 $40 \mathrm{~g} \cdot \mathrm{L}^{-1}$, 且当剥离浓度大于 $5 \mathrm{~g} \cdot \mathrm{L}^{-1}$ 后剥离体系形成透明凝胶, 58 甘氨酸插层 $\mathrm{Mg}_{3} \mathrm{Al}-\mathrm{NO}_{3} \mathrm{LDHs}$ 在甲酰胺中辅助超声处理可使剥 离浓度达到 $42.5 \mathrm{~g} \cdot \mathrm{L}^{-1}$. 9 我们在实验中发现, LDHs 的阴离子对其剥离效果影响很大, 将 $\mathrm{Mg}_{2} \mathrm{Al}-\mathrm{NO}_{3}$ LDHs 在甲酰胺中室温 $\left(18^{\circ} \mathrm{C}\right)$ 搅拌 $24 \mathrm{~h}$ 可得到稳定 的胶态分散体, 且当浓度大于 $10 \mathrm{~g} \cdot \mathrm{L}^{-1}$ 时可形成淡 蓝色透明凝胶, 而同样条件下 $\mathrm{Mg}_{2} \mathrm{Al}-\mathrm{Cl} \mathrm{LDHs}$ 只部 分剥离, 且体系极不稳定. 何书街等 ${ }^{60}$ 以甲酰胺为溶 剂对酸性橙阴离子插层的锌铝硝酸根 LDHs 进行了 剥离, 认为插入层间的酸性橙阴离子易于结合甲酰 胺分子, 甲酰胺进入层间撑大其层间距, 削弱层板 间的作用力, 从而使层板剥离.

用于剥离的 LDHs 前体通常采用恒定 $\mathrm{pH}$ 共沉 淀法制备. $\mathrm{Li}$ 等 ${ }^{61}$ 认为, 普遍采用的恒定 $\mathrm{pH}$ 共沉淀 法制备的 LDHs 前体通常尺寸较小, 剥离后片层横 向尺寸在几十纳米之间, 不易于表征且在应用方面 受到限制, 因此研究了大尺寸微米级 $\mathrm{Mg}-\mathrm{Al}-\mathrm{NO}_{3}$ LDHs 的剥离. ${ }^{61,62}$ 大尺寸微米级 LDHs 可通过四氮六 甲園(HMT) 水解法制备. ${ }^{61-64}$ 将混合金属盐溶液与 $\mathrm{HMT}$ 水溶液混合后置入自生压力釜中, $140{ }^{\circ} \mathrm{C}$ 反应 $24 \mathrm{~h}$, 利用 HMT 缓慢水解释放出的氨达到合成
LDHs 所需要的碱度, 以保证 LDHs 的成核及生长. 此方法得到的 LDHs 尺寸大且均一, 横向尺寸在 4 $\mu \mathrm{m}$ 左右. 但是, HMT 水解同时产生甲醛, 其氧化后 生成大量碳酸根, 因此所制 LDHs 层间阴离子主 要为碳酸根. 因碳酸根离子与 LDHs 层板的作用 力很强, 使得后续剥离困难, 所以利用浓盐-稀酸 $\left(\mathrm{NaNO}_{3}-\mathrm{HNO}_{3}\right)$ 法 ${ }^{63,64}$ 将层间碳酸根置换为硝酸根再 进行剥离. 将大尺寸微米级 $\mathrm{Mg}-\mathrm{Al}-\mathrm{NO}_{3} \mathrm{LDHs}$ 分散 于甲酰胺中 (浓度为 $0.5 \mathrm{~g} \cdot \mathrm{L}^{-1}$ ), 氮气保护下在振荡 器中以 $170 \mathrm{r} \cdot \mathrm{min}^{-1}$ 振荡 $12 \mathrm{~h}$, 得到完全剥离的分散 体系.

大尺寸 LDHs 也可通过尿素水解法制备. Liu 等 ${ }^{65,66}$ 采用尿素水解法合成了 $\mathrm{Co}-\mathrm{Al}$ 型 LDHs, 并考 察层间阴离子对 $\mathrm{Co}-\mathrm{Al}$ 型 $\mathrm{LDHs}$ 在甲酰胺中剥离效 果的影响. 前体制备过程为: 混合金属盐溶液与尿 素水溶液混合后 $97{ }^{\circ} \mathrm{C}$ 反应 $24 \mathrm{~h}$, 制得 $\mathrm{Co}-\mathrm{Al}-\mathrm{CO}_{3}$ LDHs; 利用浓盐-稀酸法 $(\mathrm{HCl}-\mathrm{NaCl})$ 置换碳酸根得 到氯离子 LDHs 后, 再置入含有不同阴离子的盐溶 液中, 置换得到一系列不同阴离子的 LDHs. 将含不 同阴离子的 LDHs 分别分散于甲酰胺之中(浓度均 为 $\left.1 \mathrm{~g} \cdot \mathrm{L}^{-1}\right)$, 在振荡器中以 $160 \mathrm{r} \cdot \mathrm{min}^{-1}$ 振荡 $48 \mathrm{~h}$, 检 测其剥离度. 剥离度的测定方法为: 将剥离分散体 在 $2000 \mathrm{r} \cdot \mathrm{min}^{-1}$ 下离心 $10 \mathrm{~min}$, 分离出未剥离颗粒, 干燥称重, 进而得出剥离颗粒占的比例即为剥离 度. 结果表明, LDHs 的层间阴离子对其剥离效果影 响很大, $\mathrm{Co}-\mathrm{Al}-\mathrm{NO}_{3}$ LDHs 能完全剥离, Co-Al-Cl、 $\mathrm{Co}-\mathrm{Al}_{-} \mathrm{ClO}_{4}$ (高氯酸根)、Co-Al-acetate(醋酸根) 和 Co-Al-SDS 型 LDHs 可部分剥离 (剥离度分别为 $75 \% 、 50 \% 、 60 \%$ 和 $95 \%$ ), 而 Co-Al-lactate(乳酸根)和 Co-Al-oleate(油酸根) LDHs 不能剥离. Liu 等 ${ }^{66}$ 还发 现, 不同金属元素组成的 LDHs 在甲酰胺中搅拌两 天后剥离效果不同, 例如 $\mathrm{ZnAl}_{2}-\mathrm{NO}_{3}$ 和 $\mathrm{ZnCoAl}_{2}$ $\mathrm{NO}_{3} \mathrm{LDHs}$ 剥离度较小 (约为 $40 \%$ ), 而 $\mathrm{CoAl}_{2}-\mathrm{NO}_{3}$ 和 $\mathrm{NiAl}_{2}-\mathrm{NO}_{3} \mathrm{LDHs}$ 剥离度很大, 接近 $100 \%$. Liu 等 ${ }^{65}$ 认 为 $\mathrm{LDHs}$ 在甲酰胺中的剥离过程可分为两步: 快速 溶胀和缓慢剥离(见图 2). LDHs 加入到甲酰胺中后, 其层间水分子迅速被甲酰胺取代, 层间距扩大, 形 成溶胀相; 在振荡、机械搅拌或超声等作用下, 产生 横向滑动力, 层片则被缓慢剥离.

LDHs 在甲酰胺中的剥离是目前最有效的剥离 方法. 但 $\mathrm{Ma}$ 等 ${ }^{62}$ 提出, 剥离分散体放置较长时间(如 1 个月)后, 甲酰胺会慢慢溶解 LDHs 片层, 在应用时 应予注意。 


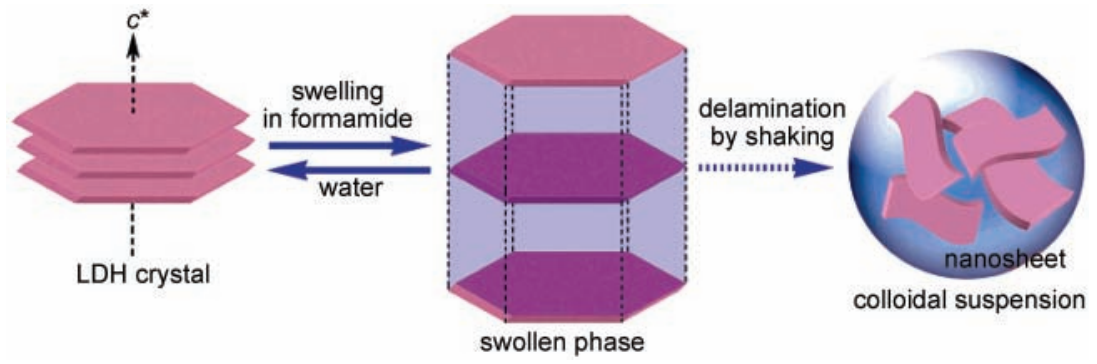

图 2 LDHs 在甲酰胺中剥离原理示意图 ${ }^{65}$

Fig.2 Schematic illustration of the possible delamination mechanism for LDHs in formamide ${ }^{65}$

\section{3 水中的剥离}

Hibino 等 ${ }^{67}$ 于 2005 年报道了 LDHs 在水中的剥 离. 将乳酸插层后的镁铝硝酸根型 LDHs 经离心、洗 涤后, 再将湿样直接分散于水中, 室温下搅拌 3-5 $\mathrm{d}$, 悬浮液可变透明, 表明 Lact-LDHs 在水中发生剥 离. 此方法的剥离浓度较高, 可达 $20 \mathrm{~g} \cdot \mathrm{L}^{-1}$. 剥离的 速度随温度的增加而加快, 当剥离温度升至 $60^{\circ} \mathrm{C}$ 时, 过夜即可完全剥离. 作为对比, 未经乳酸插层的 $\mathrm{Mg}-\mathrm{Al}-\mathrm{NO}_{3} \mathrm{LDHs}$ 即使在水中放置 3 个月也未发生 剥离.

Kannan 等 ${ }^{68}$ 利用水热处理法将镍铝和钴铝硝酸 根型 LDHs 在水中剥离. 首先, 利用 HMT 水解法制 得 LDHs 前体(组成分别为 $\left[\mathrm{Ni}_{0.66} \mathrm{Al}_{0.34}(\mathrm{OH})_{2}\right]\left(\mathrm{NO}_{3}\right)_{0.34}$. $0.51 \mathrm{H}_{2} \mathrm{O}$ 和 $\left.\left[\mathrm{Co}_{0.66} \mathrm{Al}_{0.34}(\mathrm{OH})_{2}\right]\left(\mathrm{NO}_{3}\right)_{0.34} \cdot 0.32 \mathrm{H}_{2} \mathrm{O}\right)$, 将离 心、洗涤后的 $\mathrm{LDHs}$ 湿样分散于水中 $\left(2.5 \mathrm{~g} \cdot \mathrm{L}^{-1}\right)$, 置 于自生压力釜中 $120^{\circ} \mathrm{C}$ 水热处理 $12 \mathrm{~h}$, 可发生部分 剥离. 低速 $\left(3000 \mathrm{r} \cdot \mathrm{min}^{-1}\right)$ 离心除去未剥离的 $\mathrm{LDHs}$, 得出剥离度为 $25 \%$. 实现剥离的关键是 $\mathrm{LDHs}$ 前体 必须为新制备的湿样, 若经过真空干燥则在同样条 件下不能剥离。

\section{4 其它剥离方法}

除上述三类主要剥离溶剂外, 还有文献报道了 在其它体系中的剥离. Jobbagy 等 ${ }^{69}$ 发现, 在超声条 件下以 SDS 修饰的镁铝 LDHs 可以在甲苯中发生层 板溶胀, 在四氯化碳中可实现剥离. $\mathrm{O}^{\prime}$ Leary 等 ${ }^{70}$ 发 现, $\mathrm{Zn}_{2} \mathrm{Al}$-SDS LDHs 在丙烯酸酯单体中 $70{ }^{\circ} \mathrm{C}$ 时高 速剪切(2500-3000 r $\left.\cdot \mathrm{min}^{-1}\right) 20 \mathrm{~min}$ 可发生剥离. 2011 年, Zhao 等 ${ }^{71}$ 报道了镁铝硝酸根型 LDHs 及 2羟基-4-甲氧基二苯甲酮-5-磺酸插层的 LDHs 可在 二甲基亚砜(DMSO)中发生部分剥离, LDHs 片层剥 离后以 3-6 层的状态存在于 DMSO 中. 实验表明, LDHs 在 DMSO 中的溶解度比在甲酰胺中的小得 多, 因此避免了用甲酰胺做剥离溶剂时, 体系放置 较长时间后, 甲酰胺会慢慢溶解 LDHs 片层这一缺
点. 部分剥离的状态可以保持有机分子-LDHs 之间 的主客体相互作用, 有效保护插入层间的有机分 子.

另外, 上述 LDHs 的剥离均是在液态下实现的, 剥离后的体系为胶态分散体, 无法直接得到剥离 LDHs 的固态样品, 因蒸发溶剂干燥时, 剥离的 LDHs 层片会自组装恢复原层状结构. $\mathrm{Hu}$ 等 ${ }^{72}$ 提出 利用反相微乳液法一步直接制备固态剥离 LDHs. 将混合金属盐溶液作为水相加入到异辛烷油相之 中, 同时加入十二烷基硫酸钠和丁醇作乳化剂, 形 成 W/O 型微乳液; 类似地, 将混合 $\mathrm{NaNO}_{3}$ 和 $\mathrm{NaOH}$ 的水溶液作为水相加入到异辛烷油相之中, 同时加 入十二烷基硫酸钠和丁醇作乳化剂, 形成第二个 $\mathrm{W} /$ $\mathrm{O}$ 型微乳液. 将后者逐滴滴入到前面的微乳液中形 成混合体系. 将此体系于 $75^{\circ} \mathrm{C}$ 下搅拌 $24 \mathrm{~h}$, 离心、用 丙酮洗涤后得到固态单层 LDHs, 组成为 $\mathrm{Mg}_{2} \mathrm{Al}(\mathrm{OH})_{6}$ $\left(\mathrm{C}_{12} \mathrm{H}_{25} \mathrm{SO}_{4}\right) \cdot n \mathrm{H}_{2} \mathrm{O}$. 反应过程如图 3 所示, 在油相中 分散的小液滴周围吸附有十二烷基硫酸钠, 反应过

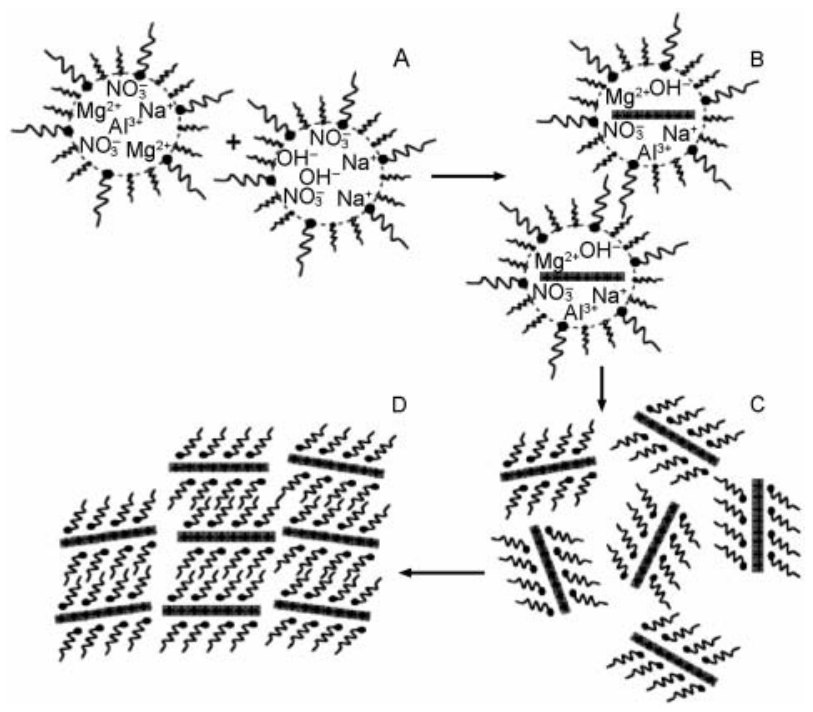

图 3 单层 LDHs 成核和生长过程示意图 ${ }^{72}$

Fig.3 Schematic illustration of nucleation and growth of LDHs platelets ${ }^{72}$ 
程中带负电的十二烷基硫酸钠吸附到逐渐生成的 LDHs 正电层板上. 液滴作为 LDHs 晶体生长的微容 器, 有限的空间限制了LDHs 生长过程中的尺寸和 厚度, 因而可直接得到横向尺寸为 $40 \mathrm{~nm}$ 的单层 LDHs.

\section{3 层状双金属氢氧化物剥离产物的表征}

LDHs 剥离产物的表征方法通常有 X射线衍射 (XRD)、透射电子显微镜 (TEM) 和原子力显微镜 (AFM)等.

\subsection{XRD 表征}

采用 XRD 技术可检测 LDHs 剥离前后晶态的 变化, 从而判断是否剥离, 同时 XRD 技术也可用于 表征剥离-重组装过程.

图 4 是表面活性剂插层后的不同金属元素组成 的 LDHs 在丁醇中剥离的胶态分散体的 XRD 图, ${ }^{54}$ 低角度特征衍射峰的消失证明 LDHs 完全被剥离, $2 \theta$ 为 $20^{\circ}$ 的宽衍射峰为载玻片的衍射峰.

图 5 是 $\mathrm{MgAl}-\mathrm{NO}_{3} \mathrm{LDHs}$ 经甘氨酸插层 $(\mathrm{MgAl}-$ (MgAl-Gly LDHs) 在甲酰胺中剥离前后及剥离后重 组装产物的 XRD 图 $\left(\mathrm{Cu} K_{a}\right) .{ }^{55}$ 其中, 图 5(a)为 $\mathrm{MgAl}-$ Gly LDHs 的 XRD 图, 呈现出 LDHs 的特征衍射峰, 即在较低衍射角区存在尖锐的衍射峰, 较高衍射角 区存在较弱的不对称衍射峰; 图 5(b)为剥离产物的 XRD 图, 可见只存在一个宽的衍射峰, 低角度区的 尖锐衍射峰消失, 表明晶体结构被破坏或类水滑石 被剥离; 图 5(c) 为将剥离后的胶态分散体逐滴滴在 玻璃片上干燥后所得产物的 XRD 图, 发现在低角度

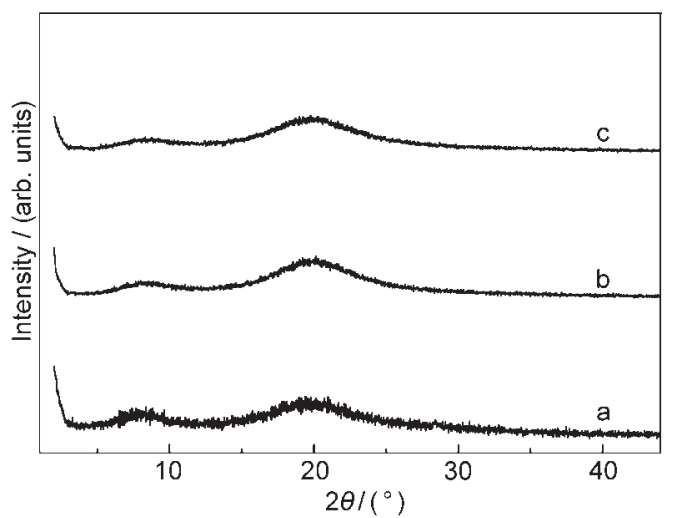

图 $4 \mathrm{Mg}_{2} \mathrm{Al}-\mathrm{SDS} \mathrm{LDH}(\mathrm{a}) 、 \mathrm{Ni}_{2} \mathrm{Al}-\mathrm{SDS} \operatorname{LDH}(\mathrm{b})$ 和 $\mathrm{Zn}_{2} \mathrm{Al}$-SDBS LDH (c) 在丁醇中剥离的胶态分散体的 $X$ 射线衍射(XRD) 图 $^{54}$

Fig.4 In situ X-ray diffraction (XRD) patterns of colloidal dispersions of $\mathrm{Mg}_{2} \mathrm{Al}-\mathrm{SDS} \mathrm{LDH}$ (a), $\mathrm{Ni}_{2} \mathrm{Al}-\mathrm{SDS}$ LDH (b), and $\mathrm{Zn}_{2} \mathrm{Al}-$ SDBS LDH (c) ${ }^{54}$
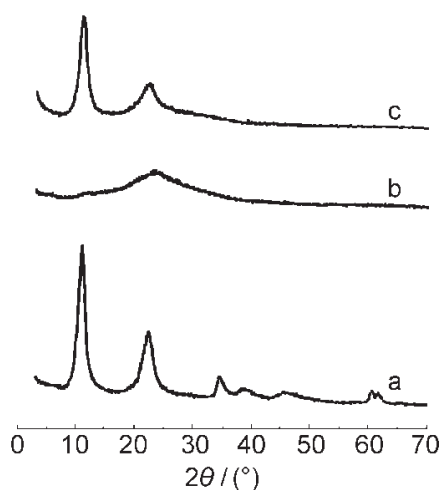

图 $5 \mathrm{MgAl}-\mathrm{Gly}$ LDHs 的 XRD 图 ${ }^{55}$

Fig.5 XRD patterns for MgAl-Gly $\mathrm{LDHs}^{55}$

(a) after preparation and drying in air, (b) 1:1 mixture with formamide indicating absence of LDHs reflections, (c) a material obtained by repeated addition of droplets of a completely delaminated mixture

区又出现了 LDHs 的特征尖锐衍射峰, 表明干燥后 单元晶片重组装又恢复了 LDHs 晶体结构.

图 6 是 $\mathrm{Co}-\mathrm{Al}-\mathrm{NO}_{3} \mathrm{LDHs}$ 在甲酰胺中剥离后的 胶态悬浮体经高速 $\left(30000 \mathrm{r} \cdot \mathrm{min}^{-1}\right)$ 离心所得到的胶 状物的 XRD 图, ${ }^{65}$ 低角度区尖锐衍射峰消失, 表明 LDHs 被剥离, 取而代之的是在 $2 \theta<15^{\circ}$ 区出现一个 无定形的峰, 是由剥离的层片无规则聚集所致, 而 在 $20^{\circ}-30^{\circ}$ 之间的衍射峰则是由甲酰胺的衍射所 致.

图 7 是 $\mathrm{Ni}-\mathrm{Al}-\mathrm{NO}_{3} \mathrm{LDH}$ 分别以水热法剥离和在 甲酰胺中剥离的产物, 经高速离心所得胶状物在放 置不同时间后的 XRD 图, ${ }^{68}$ 发现开始均已成功剥离, 但在放置一定时间后剥离的单元晶片又重组装成 为有序结构. 这个结果说明, 剥离的单元晶片在浓 度高时可自发重组装恢复 LDH 结构; 同时由图 7 也 可看出, 在水中的自发重组装过程比在甲酰胺中 快. 在水中剥离的 $\mathrm{LDH}$ 离心之后 $1 \mathrm{~h}$ 即发生重组装, 而在甲酰胺中剥离的 LDH 五天后才发生重组装.

图 8 是反相微乳液法制备的固态剥离层状双金 属氢氧化物 $\mathrm{Mg}_{2} \mathrm{Al}(\mathrm{OH})_{6}\left(\mathrm{C}_{12} \mathrm{H}_{25} \mathrm{SO}_{4}\right) \cdot n \mathrm{H}_{2} \mathrm{O}$ 样品的

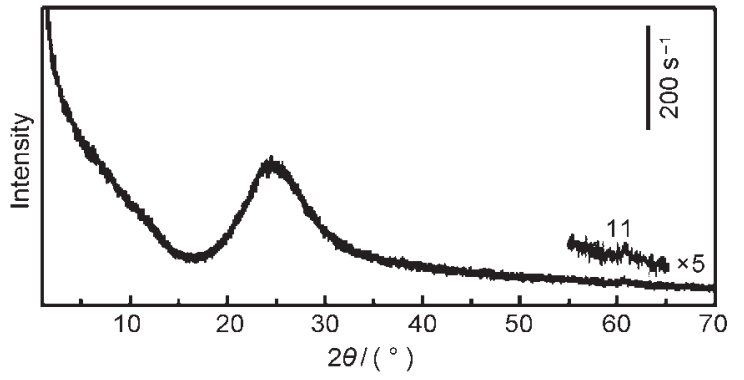

图 6 悬浮液经高速离心所得胶状物的XRD 图 ${ }^{65}$

Fig.6 XRD pattern for the colloidal aggregate centrifuged from the suspension ${ }^{65}$ 

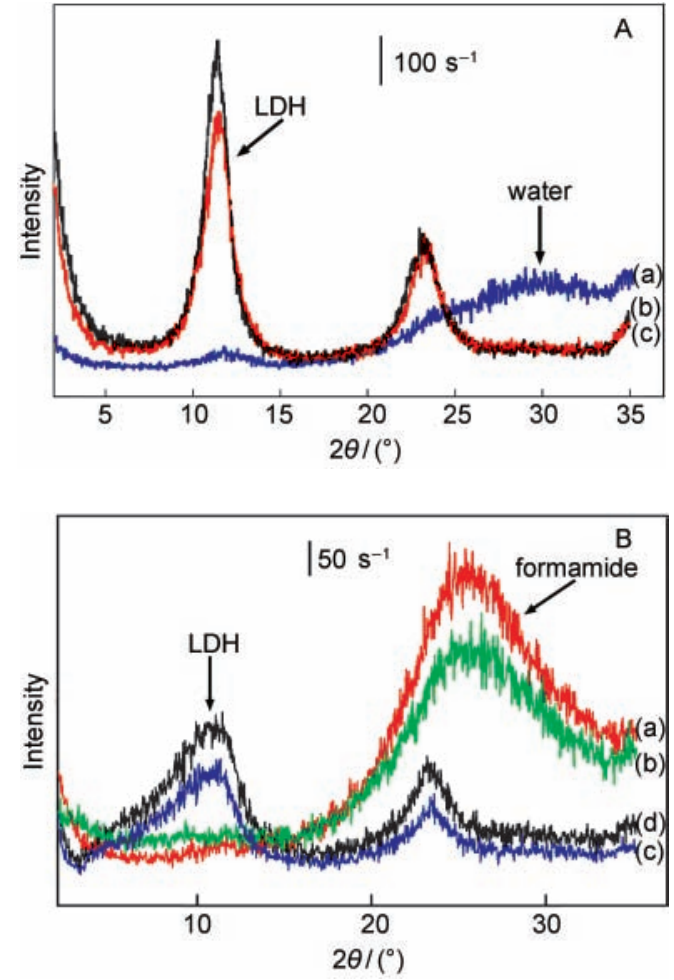

图 7 在水中剥离的 $\mathrm{Ni}-\mathrm{Al}-\mathrm{NO}_{3} \mathrm{LDH}$ 的 XRD 图 ${ }^{68}$

Fig.7 XRD patterns of water-delaminated Ni-Al-LDH ${ }^{68}$ A (a) immediately after centrifuging, A (b) after $1 \mathrm{~h}$ and A (c) after 3 $\mathrm{d}$ and formamide-delaminated Ni-Al-LDH; B (a) immediately after centrifuging, B (b) after $1 \mathrm{~d}, \mathrm{~B}$ (c) after $5 \mathrm{~d}$ and B (d) after $13 \mathrm{~d}$

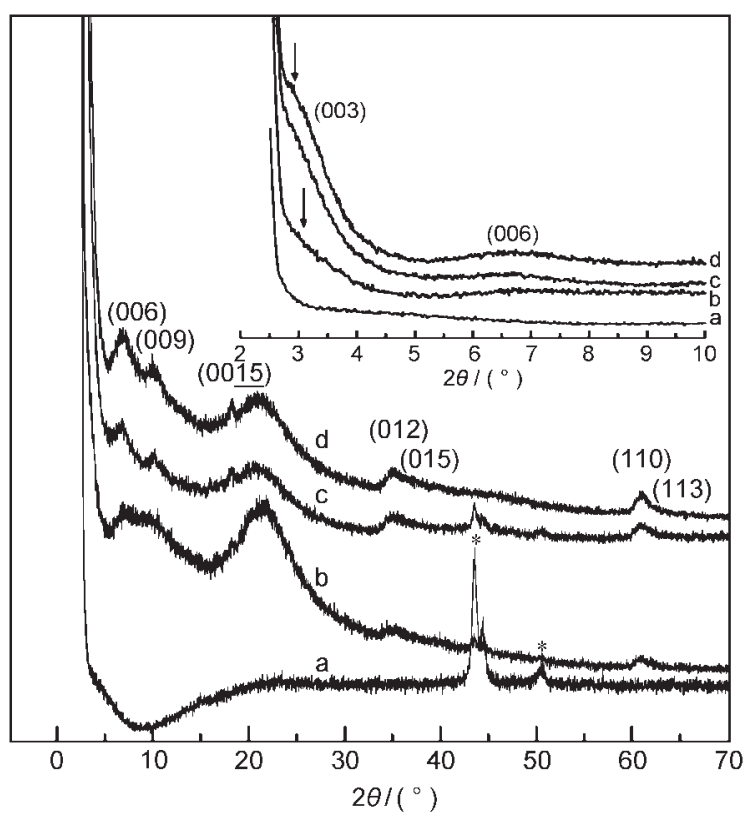

图 8 不同样品的粉末 XRD 图 ${ }^{72}$

Fig.8 Powder XRD patterns of different samples

(a) empty sample holder, (b) the gel-like product separated by centrifuge, (c) the same product after drying for $30 \mathrm{~min}$, (d) $180 \mathrm{~min}$ drying. The $2.5^{\circ}-10^{\circ}$ region is highlighted as inset. ${ }^{72}$
$\mathrm{XRD}$ 图. ${ }^{72}$ 其中, 图 $8 \mathrm{~b}$ 为刚离心之后的胶状物, 在 $7.5^{\circ}$ 和 $20^{\circ}$ 分别存在两个宽的衍射峰, 但是层状类水 滑石在低角度的特征衍射峰消失, 表明不存在层状 结构; 图 $8 \mathrm{c}$ 和 $8 \mathrm{~d}$ 分别为置于空气中室温干燥 30 和 $180 \mathrm{~min}$ 后的 XRD 图, 可见在 $7.5^{\circ}$ 的衍射峰发生分 裂, 且在 $18^{\circ}$ 处出现一个新衍射峰. 另外, 在 $2^{\circ}-10^{\circ}$ 的小角度区XRD 图中可以看到, 与空载样品台的 XRD 衍射图(图 8a) 相比, 剥离 LDHs 样品在 $3^{\circ}$ 处存 在衍射峰, 并且随干燥时间延长该衍射峰逐渐变得 明显, 这表明样品结构随干燥时间的延长逐渐由无 序变为有序, 即发生了自发重组装.

\section{2 透射电子显微镜(TEM)和原子力显微镜 \\ (AFM)表征}

TEM 和 AFM 是表征 LDHs 剥离产物形貌的直 观手段. 图 9 是 $\mathrm{Co}-\mathrm{Al}-\mathrm{NO}_{3} \mathrm{LDHs}$ 在甲酰胺中剥离产 物的 AFM 和 TEM 照片. ${ }^{65}$ 从 AFM 照片可以看到横 向尺寸在 $1 \mu \mathrm{m}$ 左右的超薄片, 还存在少量碎片片段 及尺寸大于 $2 \mu \mathrm{m}$ 的薄片, 层片形状不规则且尺寸小 于未剥离类水滑石, 这表明剥离过程中层板发生破 坏或破裂; 高度剖面图显示薄片厚度均为 $(0.80 \pm$ $0.01) \mathrm{nm}$, 与 $\mathrm{LDHs}$ 单层层板厚度 $(0.48 \mathrm{~nm})$ 和甲酰胺 单分子层厚度 $(\sim 0.3 \mathrm{~nm})$ 之和一致, 表明 LDHs 完全 剥离为单层结构. TEM 照片也观察到相同大小的薄 片, 微弱却均一的衬度表明片层极薄且厚度均匀。

图 10 是乳酸插层镁铝硝酸根型层状双金属氢 氧化物(Lact-LDHs)在水中剥离产物的 AFM 照片, ${ }^{67}$ 剖面图中可以观察到横向尺寸为 100-150 nm 的较 大剥离片, 平均厚度约 $2.5 \mathrm{~nm}$.

图 11 是 $\mathrm{Co}-\mathrm{Al}-\mathrm{NO}_{3} \mathrm{LDHs}$ 分别在甲酰胺和水中 剥离产物的 AFM 照片, ${ }^{68}$ 两种溶剂中的剥离产物均

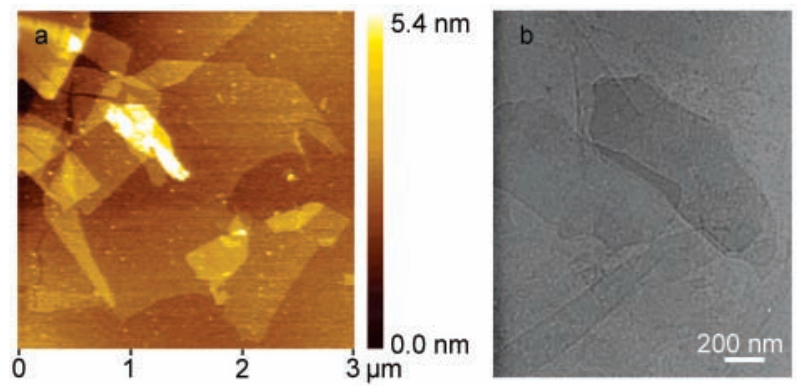

图9 剥离 $\mathrm{LDH}$ 片层 (a)在 $\mathrm{Si}$ 片上的原子力显微镜(AFM) 照片和(b)透射电镜(TEM)照片 ${ }^{65}$

Fig.9 Tapping-mode atomic force microscopy (AFM) image of the exfoliated LDH nanosheets deposited on a $\mathrm{Si}$ wafer substrate (a) and transmission electron microscopy (TEM) image of LDH nanosheets (b) ${ }^{65}$ 

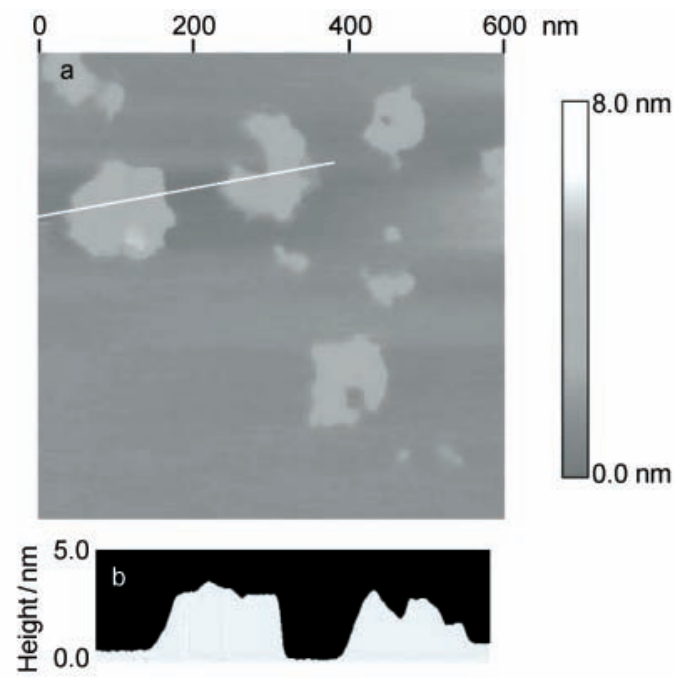

图 10 剥离样品的 AFM 图 ${ }^{67}$

Fig.10 AFM image of delaminated samples ${ }^{67}$

(a) delaminated 3:1 lact-LDH sheets on a mica substrate; (b) height profile along the white line in image (a)
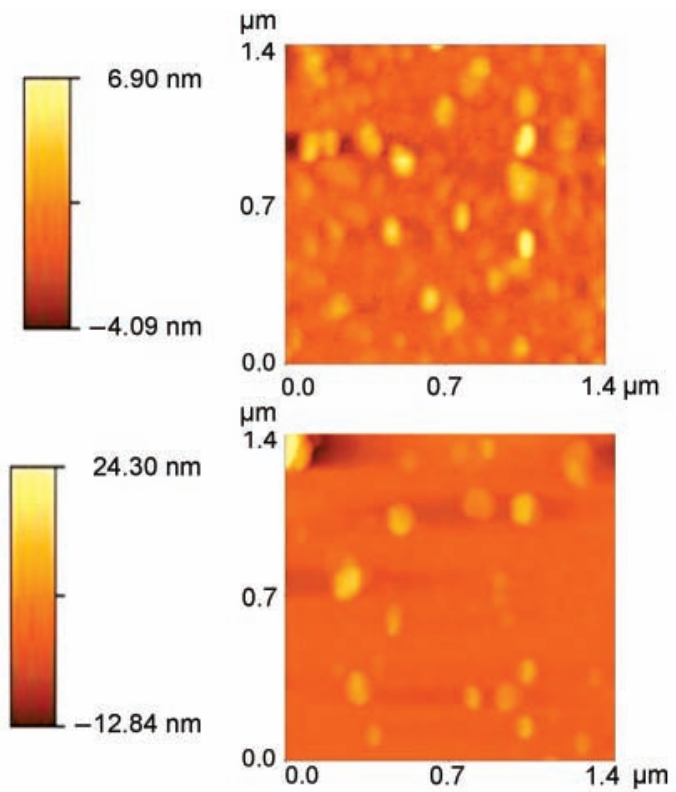

图 $11 \mathrm{Co}-\mathrm{Al}-\mathrm{NO}_{3} \mathrm{LDHs}$ 分别在(a)甲酰胺中和(b)水中剥离 产物的 AFM 照片 ${ }^{68}$

Fig.11 AFM images of Co-Al-NO $\mathrm{LDH}_{3}$ delaminated in

(a) formamide and (b) water ${ }^{68}$

为横向尺寸 100-200 nm、厚度 2-10 nm 的薄片, 表 明两种剥离溶剂(甲酰胺和水)具有相同的剥离 能力.

\section{4 层状双金属氢氧化物剥离产物的应用}

人们在剥离 $\mathrm{LDHs}$ 的应用方面也进行了多方面 的积极探索. ${ }^{62,71-87}$ 剥离后的 LDHs 层片带正电荷, 具 有分子水平的二维尺度, 可作为研究物理属性的模 型体系, 也可作为基础材料与多金属氧酸盐、聚合
物以及生物分子进行组装以构建不同功能的纳米 复合物.

\section{1 剥离 LDHs/聚合物多层超薄复合膜材料}

利用静电力通过层层组装法构建剥离 LDHs/聚 合物多层功能性薄膜是目前研究较多的课题. $\mathrm{Li}$ 等 ${ }^{62}$ 通过层层自组装, 制备了剥离 $\mathrm{Mg}-\mathrm{Al}-\mathrm{NO}_{3} \mathrm{LDH} /$ 阴离 子型聚合物(聚苯乙烯磺酸钠)多层超薄膜. 组装过 程为: 首先, 将清洗过的基片( $\mathrm{Si}$ 晶片或石英玻璃载 玻片)浸入到聚乙醇胺(PEI)水溶液中 $20 \mathrm{~min}$, 以得到 带负电的表面层; 之后以水洗涤, 再将其浸入到聚 苯乙烯磺酸钠 $(\mathrm{PSS})$ 水溶液 $\left(1 \mathrm{~g} \cdot \mathrm{L}^{-1}\right)$ 中 $20 \mathrm{~min}$, 以水 洗涤, 得到以单层 PSS 覆盖的基片表面; 随后, 再将 基片浸入到甲酰胺剥离的 LDH 胶态悬浮液中 20 min, 取出水洗, 即可在 PSS 层上覆盖一层 LDH 单元 晶片. 如此过程循环进行, 可得到 $(\mathrm{PSS} / \mathrm{LDH})_{n}$ 复合 薄膜, 以氮气气流吹干, 用于 AFM、紫外-可见光谱 和 XRD 表征(见图 12-14). 图 12 是在预覆盖的 PEI/ PSS 层上组装一层 LDHs 单元晶片后的 AFM 图, 可 以看到 $\mathrm{Si}$ 基片被横向尺寸为几百纳米至几微米之 间的 LDH 片紧密覆盖, 覆盖率达到 88\%, 这种有效 覆盖到负电表面的状态表明了剥离的 LDH层片具 有正电性. 紫外-可见光谱法可用以监测多层薄膜的 生长. 如图 13 所示, 波长 $200 \mathrm{~nm}$ 左右的吸收峰为 PSS 的紫外特征吸收峰, 其吸光度随着吸附层数增 加而线性增长, 表明了层层组装的成功进行. 图 14 为 $\mathrm{PSS} / \mathrm{LDH}$ 复合物薄膜不同层数时的 XRD 衍射 图. 单层薄膜 $2 \theta$ 在 $4.4^{\circ}$ 的衍射峰表明层间距为 $2 \mathrm{~nm}$ 左右 $(\mathrm{LDH}$ 单层厚度 $0.48 \mathrm{~nm}$ 与 $\mathrm{PSS}$ 层厚度 $1.5 \mathrm{~nm}$ 之和), 其衍射强度随层数增加而增加. 以上结果表 明了剥离的 $\mathrm{LDH}$ 层片可作为正电纳米基元用于构

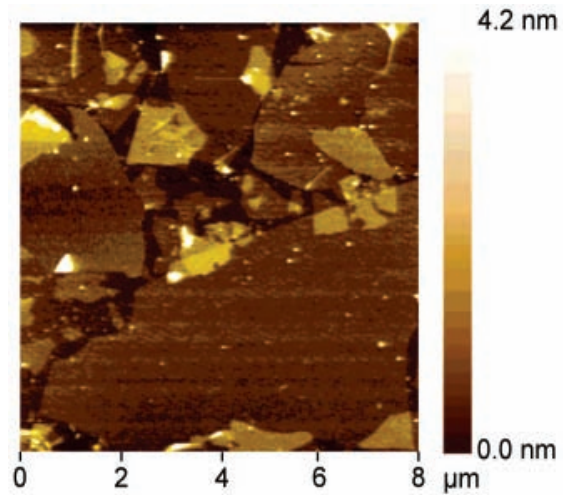

图 $12 \mathrm{Si}$ 片上第一层 $\mathrm{LDH}$ 层板的 AFM 图 ${ }^{62}$

Fig.12 AFM image of the first LDH nanosheet layer on a $\mathrm{Si}$ wafer ${ }^{62}$

nanosheet concentration: $0.5 \mathrm{~g} \cdot \mathrm{L}^{-1}$; PEI: poly ethanolamine; PSS: sodium polystyrene sulfonate 


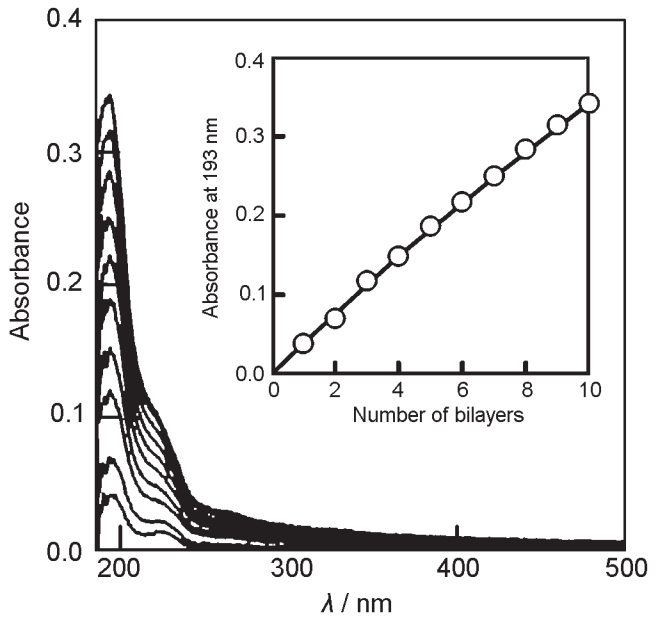

图 13 在预覆盖 PEI 的石英玻璃上制备的(PSS/LDH)n 多层膜的紫外-可见吸收光谱 ${ }^{62}$

Fig.13 UV-Vis absorption spectra of multilayer films of $(\mathrm{PSS} / \mathrm{LDH})_{n}$ prepared on a quartz glass substrate precoated with PEI $^{62}$

nanosheet concentration: $0.5 \mathrm{~g} \cdot \mathrm{L}^{-1}$; deposition time: $20 \mathrm{~min}$;

筑复合超薄膜.

Huang 等 ${ }^{73}$ 将剥离的 $\mathrm{Co}-\mathrm{Al}-\mathrm{NO}_{3} \mathrm{LDH}$ 正电层片 与聚合物(聚乙烯醇)和负电粘土(蒙脱土)片层通过 电性组装成(PVA/MMT/PVA/LDH $)_{m}$ 超薄复合膜. 层 层组装示意图如图 15 所示, 通过循环浸入-洗涤法, 依次将基片浸入聚乙烯醇(PVA)水溶液、剥离蒙脱 土(MMT)水悬浮液(将蒙脱土水悬浮液强力搅拌两 周可得到剥离液)、PVA 水溶液和甲酰胺剥离 LDHs 胶态悬浮液, 可得到 $(\mathrm{PVA} / \mathrm{MMT} / \mathrm{PVA} / \mathrm{LDH})_{m}$ 超薄 膜. PVA 与无机层板之间的氢键作用是层层组装的 驱动力. 也可通过层层组装分别制备 $(\mathrm{PVA} / \mathrm{LDH})_{m}$ 和 $(\mathrm{PVA} / \mathrm{MMT})_{m}$ 超薄膜. 图 16 为薄膜在 $190 \mathrm{~nm}$ 下的吸 光度随层数的变化, 其线性增长结果表明薄膜有规 则的逐层组装过程. 图 17 为不同层数时薄膜的

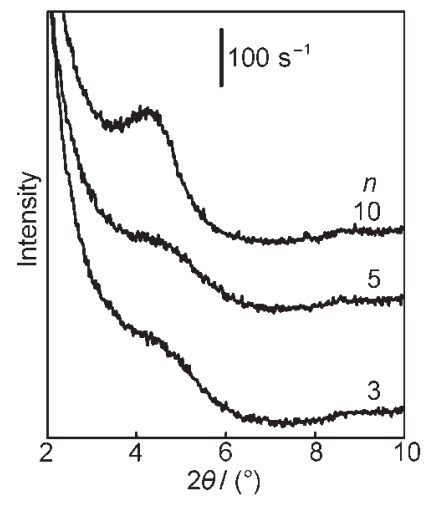

图 14 不同层数 $\mathrm{PSS} /$ 剥离 $\mathrm{Mg}-\mathrm{Al}-\mathrm{NO}_{3}(\mathrm{PSS} / \mathrm{LDH})_{n}$ 复合物 薄膜在石英玻璃片上的 XRD 衍射图 ${ }^{62}$

Fig.14 XRD patterns for the multilayer assembly of $(\mathrm{PSS} / \mathrm{LDH})_{n}$ on a quartz glass slide ${ }^{62}$

$\mathrm{XRD}$ 图, 可看到衍射强度随层数逐渐增大, 证明层 厚度逐渐增加; 经 Bragg 公式计算得到单层薄膜厚 度为 $4 \mathrm{~nm}$, 由此可知 10 层膜的厚度约为 $40 \mathrm{~nm}$.

近几年, Duan 题组 ${ }^{74-82}$ 利用层层组装制备了系 列功能超薄膜, 充分表明了层层组装法的普适性. Han 等 ${ }^{74}$ 通过尿素水解法制备了大尺寸的 MgAlLDH、NiAl-LDH 和 CoAl-LDH, 在甲酰胺中剥离后 得到一系列不同金属元素组成的带正电荷的 LDHs 层片, 和聚苯乙烯磺酸钠(PSS)层层组装成系列超薄 膜, 其构筑过程如图 18 所示. 构成的超薄膜有如下几 种: (CoAl-LDH/PSS/MgAl-LDH/PSS) ${ }_{n 2}$, (MgAl-LDH/ PSS/NiAl-LDH/PSS) $)_{n / 2}$, (CoAl-LDH/PSS/NiAl-LDH/ $P S S)_{n / 2}$, 此类超薄膜在催化、传感器等方面具有很大 的潜在应用价值. Han 等 ${ }^{75}$ 通过将剥离的 LDHs 层板 和一种荷负电的偶氮苯聚合物(PAZO)通过静电自 组装制备了多层超薄膜. 研究结果表明在紫外光和 可见光的交替作用下, $(\mathrm{LDHs} / \mathrm{PAZO})_{n}$ 薄膜中偶氮基 团可以发生可逆的顺反异构, 具备光致开关性能.

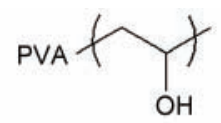

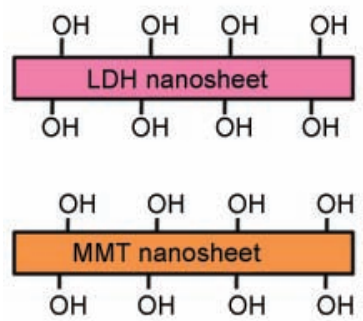

LBL

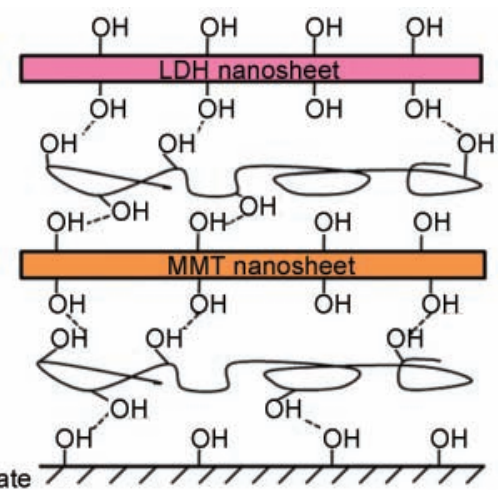

图 $15(\mathrm{PVA} / \mathrm{MMT} / \mathrm{PVA} / \mathrm{LDH})_{m}$ 超薄膜层层组装过程示意图 ${ }^{72}$

Fig.15 Schematic description of the formation of (PVA/MMT/PVA/LDH) ${ }_{m}$ film $^{72}$ 


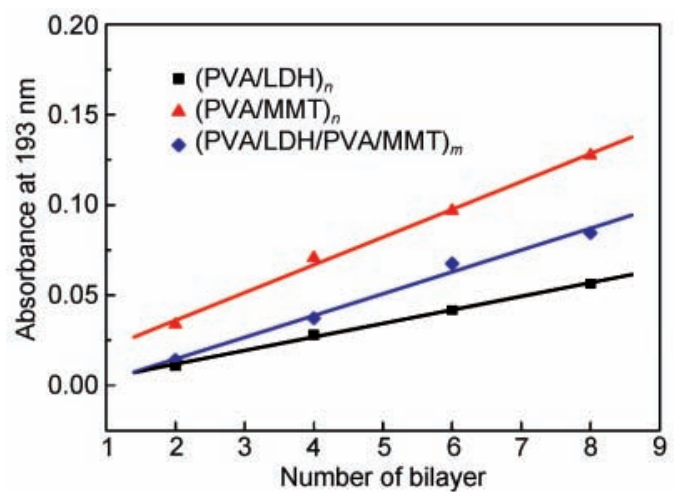

图 $16(\mathrm{PVA} / \mathrm{MMT} / \mathrm{PVA} / \mathrm{LDH})_{m}$ 超薄膜吸光度随层数的变化 ${ }^{73}$

Fig.16 Absorbance plotted of (PVA/MMT/PVA/LDH) ${ }_{m}$ against the number of deposition cycles $^{73}$

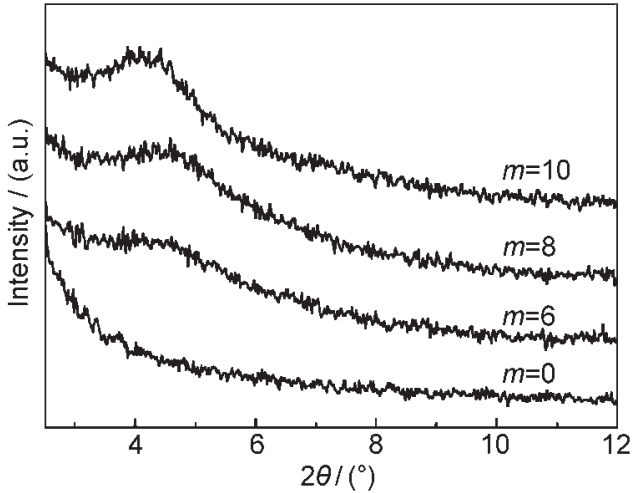

图 17 不同层数的 $(\mathrm{PVA} / \mathrm{MMT} / \mathrm{PVA} / \mathrm{LDH})_{m}$ 超薄膜 在石英玻璃上的 XRD 图谱 ${ }^{73}$

Fig.17 XRD patterns of the multilayer films of (PVA/ MMT/PVA/LDH $)_{m}$ assembled on a quartz glass slide ${ }^{73}$

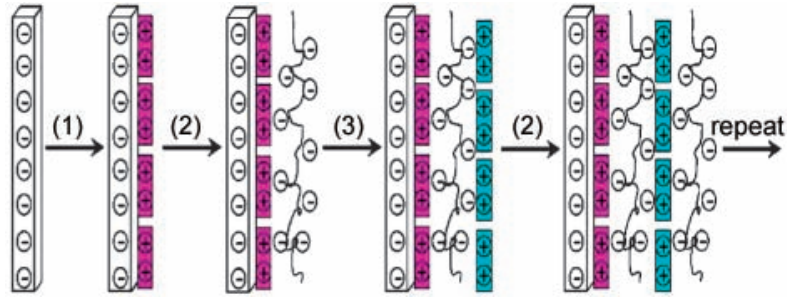

图 $18(\mathrm{CoAl}-\mathrm{LDH} / \mathrm{PSS} / \mathrm{NiAl}-\mathrm{LDH} / \mathrm{PSS})_{n / 2}$ 超薄膜 构筑过程示意图 ${ }^{74}$

Fig.18 Schematic representation of the process for the fabrication of (CoAl-LDH/PSS/NiAl-LDH/PSS $)_{n / 2}$ film $^{74}$

(1) CoAl-LDH nanosheets; (2) PSS; (3) NiAl-LDH nanosheets

Yan 等 ${ }^{76}$ 将 $\mathrm{MgAl}-\mathrm{LDHs}$ 纳米片和磺化的聚阴离子 APPP 层层组装于石英玻璃基体表面, 得到了(AP$\mathrm{PP} / \mathrm{LDHs})_{n}$ 超薄膜 $(n=3-30)$, 该超薄膜具有良好的蓝 色光致发光性能及更长的苂光寿命. 进一步研究表 明, 刚性的 LDHs 纳米片能够有效分离 APPP, 从而 避免了因聚合物链之间的 $\pi-\pi$ 相互作用所导致的红 移或者蓝移. MgAl-LDHs 纳米片还可以和阴离子聚 合物 APPV、、 含钉的配合物阴离子 ${ }^{78}$ 及金属酞菁染

料-四磺酸酞菁锌79进行层层组装制备超薄膜, 实验 发现所得超薄膜具有良好的偏振发光性能. 层层组 装主要依靠静电力进行, 因此与 LDHs 进行组装的 多为阴离子聚合物, 2010 年, Yan 等 ${ }^{80}$ 利用层层组装 首次制得了(阳离子BNMA@PVS-LDHs) 超薄膜, 首先, 光敏性阳离子 BNMA 通过静电力吸附到 PVS 聚阴离子分子链上, 形成阳离子@聚阴离子对, 具有 负电性并保留有阳离子的功能性; 之后, 将其与剥 离的 MgAl-LDHs 利用层层组装制得新型的有机-无 机超薄膜(如图 19). 此超薄膜具有长程有序结构, 有 良好的光学性能, 与 BNMA 相比具有更长的苂光寿 命和更好的极化荧光性. 2011 年, 他们 ${ }^{81}$ 又利用层层 组装法制得了具有可逆热致变色效应的荧光超薄 膜(BSB-LDHs $)_{n}$, 在实际应用中此薄膜具有高的光热稳定性, 可用于制备发光传感器, 分子温度计等. Shao 等 ${ }^{82}$ 利用层层组装法制备了剥离 $\mathrm{Co}-\mathrm{Al}^{-}-\mathrm{NO}_{3}$ LDH 层板与卟啉组成的超薄膜, 并发现此薄膜具有 优异的电催化性能.

\section{2 剥离 LDHs/大分子纳米杂化物}

LDHs 剥离层板的另一重要应用是将其与大分 子或生物分子进行重组装以制备新型纳米杂化材 料.

杨德宝 ${ }^{83}$ 将乳酸插层镁铝 LDHs 先在水中加热 回流 $9 \mathrm{~h}$ 制得剥离产物, 再与猪脂肪胰酶进行自组 装制备了生物-LDHs 纳米杂化物. 组装过程为: 将一 定量的猪脂肪胰酶加入到 HCl-tris 缓冲液中, 再与 剥离 LDHs 胶态溶液混合, 氮气保护下缓慢搅拌 30

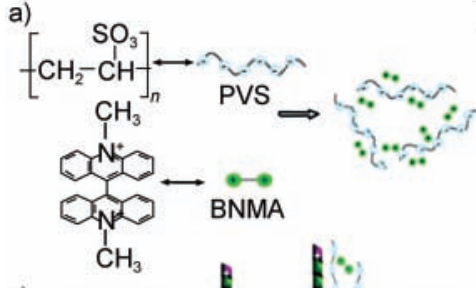

c)

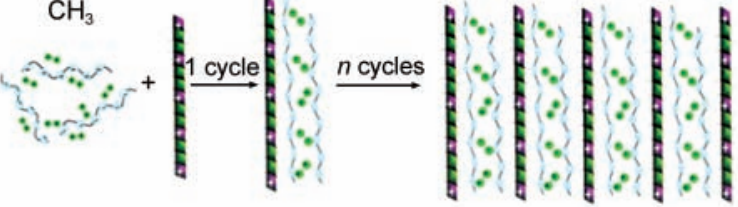

图 $19(\mathrm{BNMA} @ \mathrm{PVS} / \mathrm{LDH})_{n}$ 超薄膜(UTF)组装过程的 示意图 ${ }^{80}$

Fig.19 Scheme of assembly process for (BNMA@PVS/ LDH $)_{n}$ super thin film (UTF) ${ }^{80}$

a) The chemical formula of bis( $N$-methylacridinium) cation (BNMA) and polyvinylsulfnate (PVS), formed BNMA@PVS pair in solution; b) the representation of one Mg-Al-layered double hydroxide monolayer (Mg-Al-LDH); c) the assembly process for (BNMA@PVS/LDH) ${ }_{n}$ UTF 
$h$, 抽滤后真空干燥得组装产物. 研究证明组装产物 的酶活性极大增强. 酶与剥离 LDHs 晶片之间主要 靠静电作用和氢键作用进行组装, 组装过程符合准 二级动力学方程, 在组装量小于最大单层饱和吸附 量时组装平衡等温线符合 Langmuir 方程.

Huang 等 ${ }^{84,85}$ 通过溶胀-重组装方法将水溶性大 分子硫桥杯 4 芳烃四磺酸钠(TCAS) 与剥离 LDHs 组 装成纳米杂化物. 首先, 将适量 $\mathrm{Mg}-\mathrm{Al}-\mathrm{NO}_{3} \mathrm{LDHs}$ 加 入到甲酰胺中, 静置平衡 $24 \mathrm{~h}$ 得到 LDHs 溶胀相; 在 此溶胀相中加入适量 TCAS 或其碱水溶液, 磁力摚 拌 $24 \mathrm{~h}$ 使其自组装, $18000 \mathrm{r} \cdot \mathrm{min}^{-1}$ 下离心洗涤得到

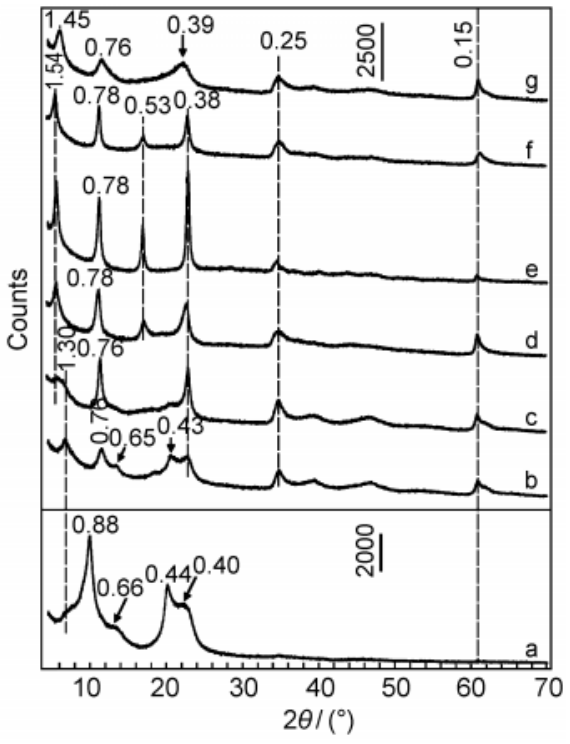

图 20 重组装样品的 XRD 图 ${ }^{85}$

Fig.20 XRD patterns of the restored samples ${ }^{85}$ (a) RC-0.01, (b) RC-0.02, (c) RC-0.04, (d) RC-0.05, (e) RC-0.075,

(f) RC-0.15, (g) RC-0.15-NaOH. RC: restored composite; $x$ in RC- $x$ is mass of TACS; TACS: 4 arene IV thiacalix sodium
最终产物. XRD 和元素分析等证明制得了纳米杂化 物. 图 20 为不同条件下制得的纳米杂化物的 XRD 图, 发现层间距随初始TCAS 浓度的增大而增加. 图 21 为插层过程示意图. TCAS 阴离子与溶胀的 LDHs 层板间的静电作用使得 TCAS 分子吸附于层板间, 形成三明治夹心结构. 当 TCAS 浓度较低时, 分子间 相互作用较弱, 形成的是单层结构, 层间距为 1.30 $\mathrm{nm}$ (图 20(c-e)); 随着 TCAS 浓度增加, 分子间的 $\pi-\pi$ 相互作用增强, 形成类似粘土结构的“顶对底”的层 间结构, 此结构具有较大的层间距, 为 $1.54 \mathrm{~nm}$ (图 $20 f$ ); 图 $20 \mathrm{~g}$ 是将 TCAS 的碱水溶液与 LDHs 的甲酰 胺溶胀相进行自组装所得产物的 XRD 图, TCAS 电 荷的增多导致 TCAS 与层板间静电作用力增大, 使 其层间距稍有降低, 即由 $1.54 \mathrm{~nm}$ 降至 $1.45 \mathrm{~nm}$.

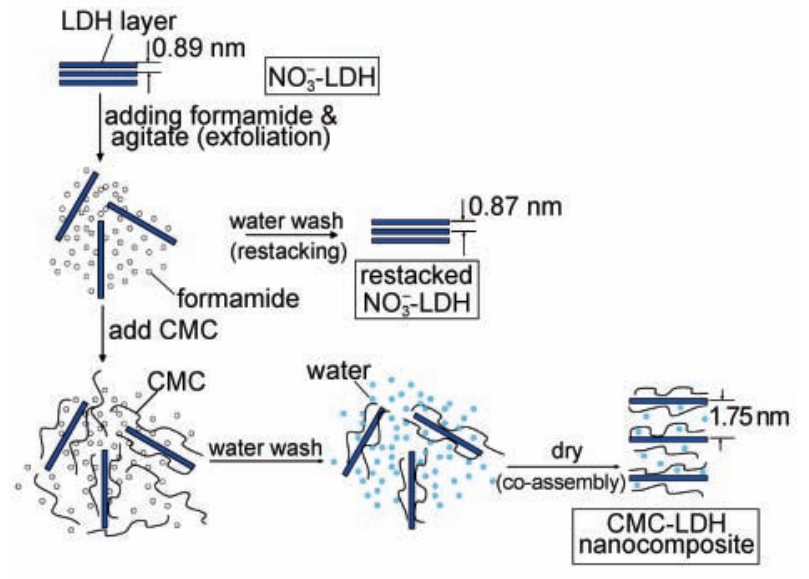

图 22 CMC-LDH 纳米杂化物形成过程的示意图 ${ }^{86}$ Fig.22 Sketch presentation of the formation progress of CMC-LDH nanocomposite ${ }^{86}$ CMC: carboxymethyl cellulose

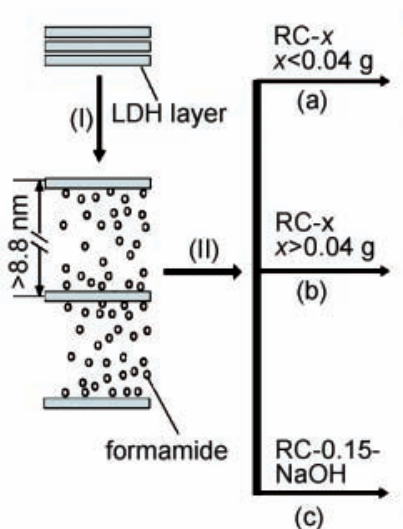

(c)
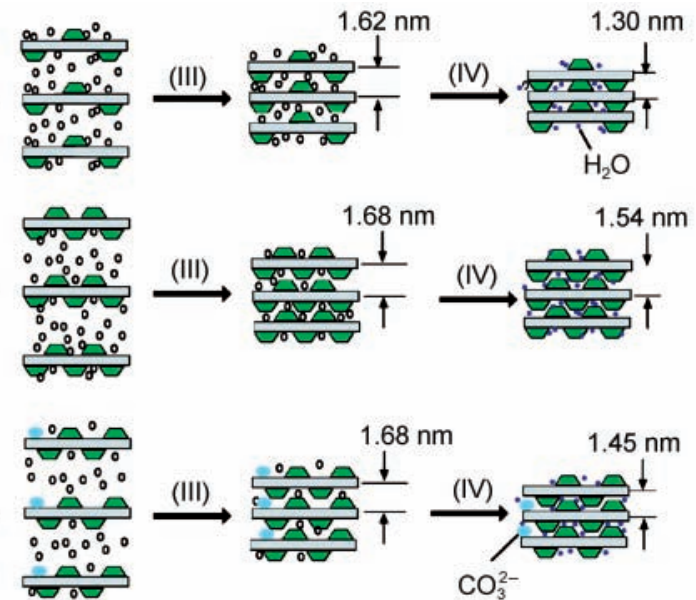

(I) swelling; (II) adding TCAS; (III) restoration; (IV) water-washing and drying

图 21 TCAS-LDHs 纳米杂化物的形成过程及其结构示意图 ${ }^{85}$

Fig.21 Schematic representation of the formation and structure of the different TCAS-LDHs samples ${ }^{85}$ 
LDHs 层片与 TCAS 的组装过程分为两步: 静电吸引 和自组装. 静电作用是自组装的主导因素, 组装后 的层间排布结构由进入层间的大分子浓度决定. 实 验证明, 组装入层板间的 TCAS 分子比纯 TCAS 分 子具有更高的热稳定性, 热分解温度提高了 $100^{\circ} \mathrm{C}$.

Kang 等 ${ }^{86}$ 通过剥离-重组装方法将羧甲基纤维 素 $(\mathrm{CMC})$ 与剥离 $\mathrm{LDHs}$ 组装成纳米杂化物. 首先, 将 适量 $\mathrm{Mg}-\mathrm{Al}-\mathrm{NO}_{3} \mathrm{LDHs}$ 加入到甲酰胺中, $160 \mathrm{r} \cdot \mathrm{min}^{-1}$ 下振荡 $24 \mathrm{~h}$ 得到 LDHs 剥离的胶态分散体; 在此分 散体中加入 $\mathrm{CMC}$ 的甲酰胺溶液, 磁力摚拌 $3 \mathrm{~h}$ 后离

(a)

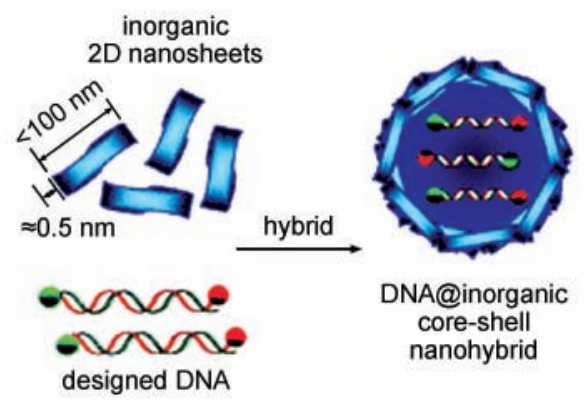

心、水洗、 $40{ }^{\circ} \mathrm{C}$ 下真空干燥得到最终产物. 水洗的过 程除去了甲酰胺, 而 $\mathrm{CMC}$ 与 $\mathrm{LDHs}$ 层片间强烈的静 电作用使 CMC 包住层片形成稳定的水分散液, 在 干燥的过程中, 重新组装为层状结构, 形成了 CMC-LDHs 纳米杂化物. 插层过程示意图见图 22. 通过 XRD 和红外等表征手段证明了 CMC-LDHs 纳 米杂化物的形成. 实验表明, 组装入层板间的 CMC 比纯 $\mathrm{CMC}$ 具有更高的热稳定性, 热分解温度提高 了 $160^{\circ} \mathrm{C}$.

Park 等 ${ }^{87}$ 将剥离的 MgAl-LDH 的胶体悬浮液与

(b)

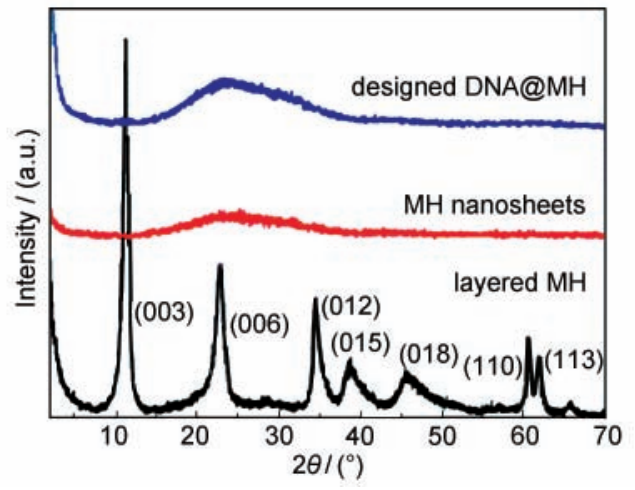

图 23 (a) DNA 核@无机壳结构示意图及(b)金属氢氧化物、单层纳米片及DNA 核@MH 壳纳米杂化物的 XRD 图 ${ }^{87}$

Fig.23 (a) Scheme for the designed DNA@inorganic core-shell nanohybrid and (b) XRD patterns of the layered MH (metal hydroxide), MH nanosheets and DNA@MH nanohybrid ${ }^{87}$
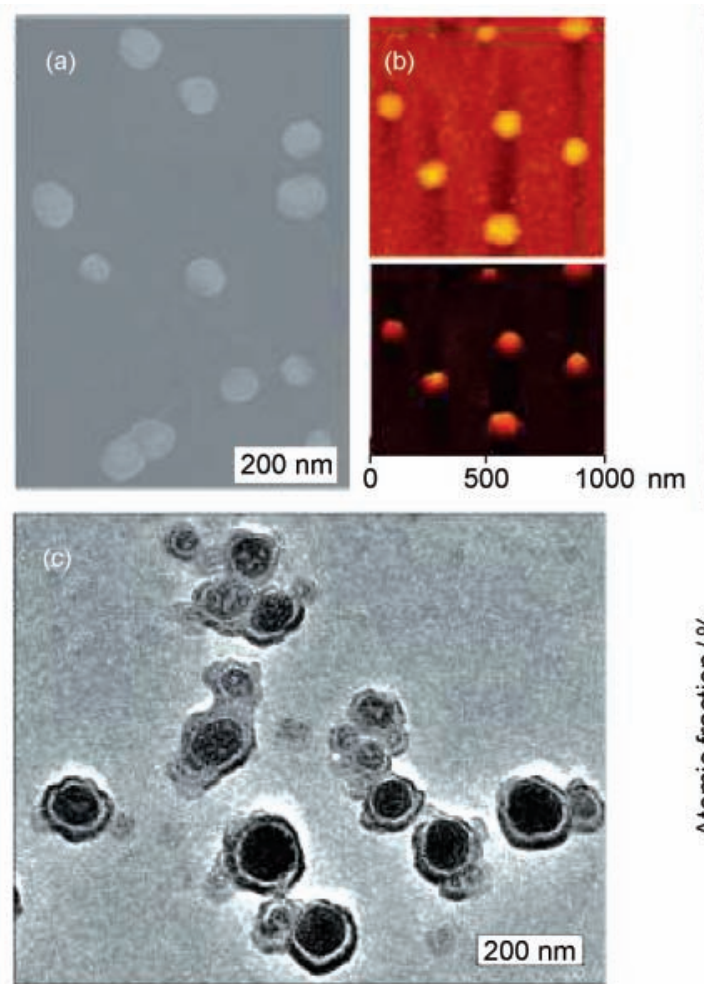
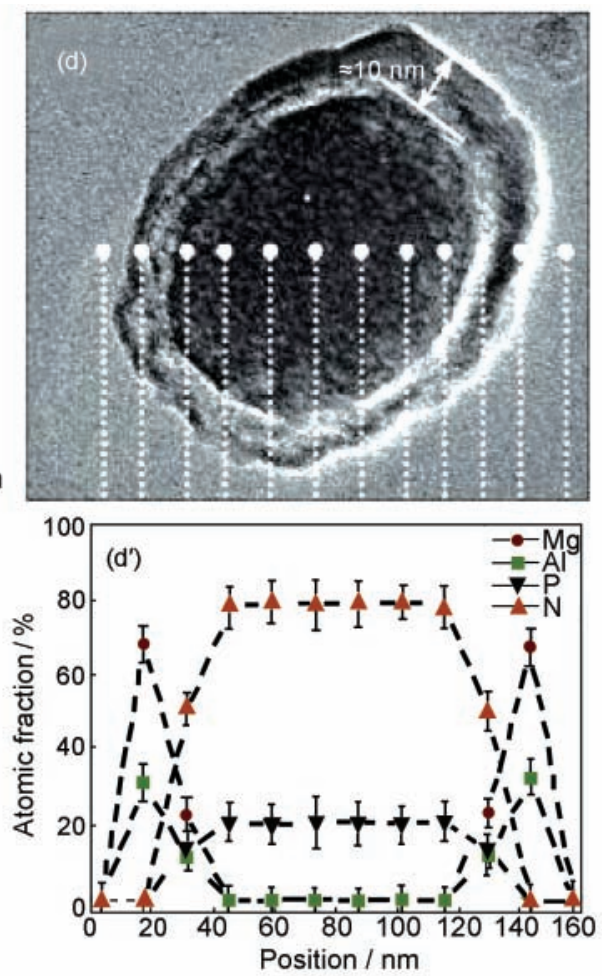

图 24 DNA 核@MH 壳结构的(a) SEM、(b) AFM、(c) 偏振 TEM 图及(d, $d^{\prime}$ )在离散过程中 EDS 线性扫描剖面图 ${ }^{87}$

Fig.24 (a) SEM image, (b) AFM image, and (c) cross section TEM image of the DNA core@MH shell nanohybrid and $\left(d, d^{\prime}\right)$ EDS linescan profile of the cross-sectional DNA core@MH shell nanohybrid at discrete steps ${ }^{87}$ 
DNA 分子的水/甲酰胺溶液混合、搅拌、冻干后, 得 到了具核壳结构的 DNA 核@无机壳的纳米杂化物 (如图 23 所示). 他们认为, 组装过程中, 静电作用使 得单层 LDH纳米片的边缘会沿球状的 DNA 分子卷 曲排布, 同时由于水的存在, 其余单层又会重组装 为多层, 并且组装沿这一球状层进行, 从而形成球 状无机外壳. 通过 SEM、AFM 等进行了表征(图 24), 核壳纳米粒子尺寸在 $120 \mathrm{~nm}$ 左右, 壳厚度 $10 \mathrm{~nm}$. EDS 线性扫描充分证明了外层壳是由 $\mathrm{LDH}$ 构成 $(\mathrm{Mg}, \mathrm{Al})$ 和内层核由 $\mathrm{DNA}(\mathrm{P}, \mathrm{N})$ 构成, 组成比分析结 果表明, $\mathrm{Mg} / \mathrm{Al}$ 之比为 $2.0, \mathrm{~N} / \mathrm{P}$ 之比为 3.7 , 与元素分 析结果一致,确证了核壳结构的形成. 此类具核壳 结构的纳米杂化物可用于高级基因传递系统及生 物医学诊断学等领域.

\section{5 总结与展望}

综上所述, 有关 LDHs 剥离的研究已有系列报 道, 发现了一些有效的剥离方法和溶剂, 但有关剥 离机理的研究还很少, 特别是剥离过程热力学和动 力学还鲜涉及.

剥离的 LDHs 纳米片带结构正电荷, 可被看做 “无机高分子”, 具有纳米尺度的开放结构, 既可作 为理论研究模型, 又可作为新型基元构建纳米复合 结构或材料, 具有广阔的应用前景, 但目前相关的 研究报道还不多. 预计今后 LDHs 的剥离-重组装在 制备复合薄膜和有机-LDHs 纳米杂化物等方面的应 用将成为研究热点之一.

\section{References}

(1) Goh, K. H.; Lim, T. T.; Dong, Z. L. Water Res. 2008, 42, 1343.

(2) Cavani, F.; Trifirò, F.; Vaccari, A. Catal. Today 1991, 11, 173.

(3) Angelo, V. Catal. Today 1998, 41, 53.

(4) Hou, W. G.; Zhang, C. G.; Sun, D. J.; Liang, X. L.; Wang, G. T. Chem. J. Chin. Univ. 1995, 16, 1292. [侯万国, 张春光, 孙德 军, 梁晓丽, 王果庭. 高等学校化学学报, 1995, 16, 1292.]

(5) Kohjiyo, S.; Sato, T.; Nakayama, T.; Yamashita, S. Makromol. Chem. Rapid Commun. 1981, 2, 231.

(6) Reichle, W. T. J. Catal. 1980, 63, 295.

(7) Drezdon, M. A. Inorg. Chem. 1988, 27, 4628.

(8) Kumbhar, P. S.; Sanchez-Valente, J.; Lopez, J.; Figueras, F. Chem. Commun. 1998, No. 5, 535.

(9) Choudary, B. M.; Kantam, M. L.; Reddy, C. R. V.; Rao, K. K.; Figueras, F. J. Mol. Catal. A-Chem. 1999, 146, 279.

(10) Pérez-Ramírez, J.; Mul, G.; Kapteijn, F.; Moulijn, J. A. J. Mater. Chem. 2001, 11, 821.

(11) Kumbhar, P. S.; Sanchez-Valente, J.; Figueras, F. Chem.
Commun. 1998, No. 10, 1091.

(12) Pérez, M. R.; Pavlovic, I.; Barriga, C.; Cornejob, J.; Hermosínb, M. C.; Ulibarri, M. A. Appl. Clay Sci. 2006, 32, 245.

(13) Ulibarri, M. A.; Pavlovic, I.; Hermosin, M. C.; Cornejo, J. Appl. Clay Sci. 1995, 10, 131.

(14) Sood, A. Process for Removing Heavy Metal ions from Solutions Using Adsorbents Containing Activated Hydrotalcite. US Patent 4,752,397, Jan, 1988.

(15) Su, Y. L.; Hou, W. G.; Sun, D. J.; Liu, S. Y.; Zhang, C. G. Chem J. Chin. Univ. 1999, 20, 1012. [苏延否, 侯万国, 孙德军, 刘尚 营, 张春光. 高等学校化学学报, 1999, 20, 1012.]

(16) Xia, C. Y.; Hou, W. G.; Sun, D. J.; Wang, G. T. Chin. J. Inorg. Chem. 1996, 12, 368. [夏春友, 侯万国, 孙德军, 王果庭. 无机 化学学报, 1996, 12, 368.]

(17) Pinnavaia, T.; Constantino, V. R. L. Inorg. Chem. 1995, 34, 883.

(18) Costantino, U.; Casciola, M.; Massinelli, L.; Vivani, R. Solid State Ionics 1997, 97, 203.

(19) Rives, V.; Ulibarri, M. A. Coord. Chem. Rev. 1999, 181, 61.

(20) Dukka, P. K.; Puri, M. J. Phys. Chem. 1989, 93, 376.

(21) Nijs, H.; Clearfield, A.; Vansant, E. F. Microporous Mesoporous Mat. 1998, 23, 97.

(22) Kanezaki, E. Mater. Res. Bull. 1999, 34, 1435.

(23) Rey, S.; Mérida-Robles, J.; Han, K. S.; Guerlou-Demourgues, L.; Delmas, C.; Duguet, E. Polym. Int. 1999, 48, 277.

(24) Millange, F.; Walton, R. I.; Lei, L. X.; O'Hare, D. Chem. Mater. 2000, 12, 1990.

(25) Prevot, V.; Forano, C.; Besse, J. P. Appl. Clay Sci. 2001, 18, 3.

(26) Crepaldi, E. L.; Pavan, P. C.; Valim, J. B. J. Mater. Chem. 2000, 10, 1337.

(27) Abend, S.; Bonnke, N.; Gutschner, U.; Lagaly, G. Colloid Polym. Sci. 1998, 276, 730.

(28) Itaya, K.; Chang, H. C.; Uchida, L. Inorg. Chem. 1987, 26, 624.

(29) Mousty, C.; Therias, S.; Forano, C.; Besse, J. P. J. Electroanal. Chem. 1994, 374, 63.

(30) Li, L. F.; Hou, W. G.; Jiao, Y. N.; Liu, C. X. Acta Phys. -Chim. Sin. 2004, 20, 459. [李丽芳, 侯万国, 焦燕妮, 刘春霞. 物理化 学学报, 2004, 20, 459.]

(31) Liu, J. J.; Li, F.; Evans, D. G.; Duan, X. Chem. Commun. 2003, No. 4,542 .

(32) Ogawa, M.; Kuroda, K. Chem. Rev. 1995, 95, 399.

(33) Tagaya, H.; Ogata, S.; Nakano, S.; Kadokawa, J. I.; Karasu, M.; Chiba, K. J. Inclusio Phenom. Macrocyclic Chem. 1998, 31, 231.

(34) Robins, D. S.; Dutta, P. K. Langmuir 1996, 12, 402.

(35) Nakajima, H.; Ishino, S.; Masuda, H.; Shimosaka, T.; Nakagama, T.; Hobo, T.; Uchiyama, K. Chem. Lett. 2005, 34, 358.

(36) Ambrogi, V.; Fardella, G.; Grandolini, G.; Nocchetti, M.; Perioli, L. J. Pharm. Sci. 2003, 92, 1407.

(37) Tyner, K. M.; Schiffman, S. R.; Giannelis, E. P. J. Control. Release 2004, 95, 501. 
(38) Sun, H.; Zhang, H.; Evans, D. G.; Duan, X. Chin. Sci. Bull. 2004, 49, 2525. [孙 辉, 张 慧, Evans, D. G., 段 雪. 科学 通报, 2004, 49, 2525.]

(39) Gordijo, C. R.; Barbosa, C. A. S.; Ferreira, A. M. D. C.; Constantino, V. R. L.; Silva, D. O. J. Pharm. Sci. 2005, 94, 1135.

(40) Khan, A. I.; Lei, L. X.; Norquist, A. J.; O'Hare, D. Chem. Commun. 2001, 2342.

(41) Hou, W. G.; Jin, Z. L. Colloid Polym. Sci. 2007, 285, 1449.

(42) Del Arco, M.; Gutiérrez, S.; Martí n, C.; Rives, V.; Rocha, J. J. Solid State Chem. 2004, 177, 3954.

(43) Wei, M.; Shi, S.; Wang, J.; Li, Y.; Duan, X. J. Solid State Chem. 2004, 177, 2534.

(44) Del Arco, M.; Cebadera, E.; Gutiérrez, S.; Martín, C.; Montero, M. J.; Rives, V.; Rocha, J.; Sevilla, M. A. J. Pharm. Sci. 2004, 93, 1649.

(45) Xiao, R.; Wang, W. R.; Pan, L. L.; Zhu, R. R.; Yu, Y. C.; Li, H. P.; Liu, H.; Wang, S. L. J. Mater. Sci. 2011, 46, 2635.

(46) Choy, J. H.; Kwak, S. Y.; Park, J. S.; Jeong, Y. J.; Portier, J. J. Am. Chem. Soc. 1999, 121, 1399.

(47) Kwak, S. Y.; Jeong, Y. J.; Park, J. S.; Choy, J. H. Solid State Ionics 2002, 151, 229.

(48) Oh, J. M.; Kwak, S. Y.; Choy, J. H. J. Phys. Chem. Solids 2006, $67,1028$.

(49) Thyveetil, M. A.; Coveney, P. V.; Greenwell, H. C.; Suter, J. L. J. Am. Chem. Soc. 2008, 130, 4742.

(50) Liu, C. X.; Hou, W. G.; Li, L. F.; Li, Y.; Liu, S. J. J. Solid State Chem. 2008, 181, 1729.

(51) Adachi-Pagano, M.; Forano, C.; Besse, J. P. Chem. Commun. 2000, 91.

(52) Leroux, F.; Adachi-Pagano, M.; Intissar, M.; Chauvière, S.; Forano, C.; Besse. J. P. Mater. Chem. 2001, 11, 105.

(53) Singh, M.; Ogden, M. I.; Parkinson, G. M.; Buckley, C. E.; Connolly, J. J. Mater. Chem. 2004, 14, 871.

(54) Venugopal, B. R.; Shivakumara, C.; Rajamathi, M. J. Colloid Interface Sci. 2006, 294, 234.

(55) Hibino, T.; Jones, W. J. Mater. Chem. 2001, 11, 1321.

(56) Hibino, T. Chem. Mater. 2004, 16, 5482.

(57) Guo, Y.; Zhang, H.; Zhao, L.; Li, G. D.; Chen, J. S.; Xu, L. J. Solid State Chem. 2005, 178, 1830.

(58) Wu, Q.; Olfsen, A.; Vistad, Ø. B.; Roots, J.; Norby, P. J. Mater. Chem. 2005, 15, 4695.

(59) Wu, Q.; Sjåstad A. O.; Vistad, Ø. B.; Knudsen, K. D.; Roots, J.; Pedersen, J. S.; Norby, P. J. Mater. Chem. 2007, 17, 965.

(60) He, S. H.; Pu, M.; Li, J. N.; He, J.; Evans, D. G. Acta Phys. -Chim. Sin. 2010, 26, 259. [何书街, 蒲 敏, 李军男, 何 静, Evans, D. G. 物理化学学报, 2010, 26, 259.]

(61) Li, L.; Ma, R. Z.; Ebina, Y.; Iyi, N.; Sasaki, T. Chem. Mater. 2005, 17, 4386 .

(62) Ma, R. Z.; Liu, Z. P.; Li, L.; Iyi, N.; Sasaki, T. J. Mater. Chem 2006, 16,3809

(63) Iyi, N.; Matsumoto, T.; Kaneko, Y.; Kitamura, K. Chem. Lett.
2004, 33, 1122 .

(64) Iyi, N.; Okamoto, K.; Kaneko, Y.; Matsumoto, T. Chem. Lett. 2005, 34, 932.

(65) Liu, Z. P.; Ma, R. Z.; Osada, M.; Iyi, N.; Ebina, Y.; Takada, K.; Sasaki, T. J. Am. Chem. Soc. 2006, 128, 4872.

(66) Liu, Z. P.; Ma, R. Z.; Ebina, Y.; Iyi, N.; Takada, K.; Sasaki, T. Langmuir 2007, 23, 861

(67) Hibino, T.; Kobayashi, M. J. Mater. Chem. 2005, 15, 653.

(68) Antonyraj, C. A.; Koilraj, P.; Kannan, S. Chem. Commun. 2010, 46, 1902.

(69) Jobbagy, M.; Regazzoni, A. E. J. Colloid Interface Sci. 2004, 275,345 .

(70) O'Leary, S.; O'Hare, D.; Seeley, G. Chem. Commun. 2002, 1506.

(71) Zhao, Y.; Yang, W. D.; Xue, Y. H.; Wang, X. G.; Lin, T. J. Mater. Chem. 2011, 21, 4869.

(72) Hu, G.; Wang, N.; O’Hare, D.; Davis, J. Chem. Commun. 2006, 287.

(73) Huang, S.; Cen, X.; Peng, H. D.; Guo, S. Z. Wang, W. Z.; Liu, T. X. J. Phys. Chem. B 2009, 113, 15225 .

(74) Han, J. B.; Lu, J.; Wei, M.; Wang, Z. L.; Duan, X. Chem. Commun. 2008, 5188.

(75) Han, J. B.; Yan, D. P.; Shi, W. Y.; Ma, J.; Yan, H.; Wei, M.; Evans, D. G.; Duan, X. J. Phys. Chem. B 2010, 114, 5678.

(76) Yan, D. P.; Lu, J.; Wei, M.; Han, J. B.; Ma, J.; Li, F.; Evans, D. G.; Duan, X. Angew. Chem. Int. Edit. 2009, 121, 3119.

(77) Yan, D. P.; Lu, J.; Ma, J.; Wei, M.; Li, F.; Wang, X. R.; Evans, D. G.; Duan, X. Langmuir 2010, 26, 7007.

(78) Yan, D. P.; Lu, J.; Wei, M.; Ma, J.; Li, F.; Evans, D. G.; Duan, X. Chem. Commn. 2009, 6358.

(79) Yan, D. P.; Qin, S. H.; Chen, L.; Lu, J.; Ma, J.; Wei, M.; Evans, D. G.; Duan, X. Chem. Commun. 2010, 46, 8654.

(80) Yan, D. P.; Lu, J.; Chen, L.; Qin, S. H.; Ma, J.; Wei, M.; Evans, D. G.; Duan, X. Chem. Commun. 2010, 46, 5912.

(81) Yan, D. P.; Lu, J.; Ma, J.; Wei, M.; D. G.; Duan, X. Angew. Chem. Int. Edit. 2011, 123, 746.

(82) Shao, M. F.; Han, J. B.; Shi, W. Y.; Wei, M.; Duan, X. Electrochem. Commun. 2010, 12, 1077.

(83) Yang, D. B. The Assembly of Delaminated Layered Double Hydroxides with Porcine pancreas Lipase. Master Dissertation, Beijing University of Chemical Technology, Beijing, 2007. [杨 德宝. 剥离水滑石与猪胰脂肪酶的自组装[M]. 北京: 北京化工 大学, 2007.]

(84) Huang, G. L.; Ma, S. L.; Zhao, X. H.; Yang, X. J.; Ooib, K. Chem. Commun. 2009, No. 3, 331.

(85) Huang, G. L.; Ma, S. L.; Zhao, X. H.; Yang, X. J.; Ooib, K. Chem. Mater. 2010, 22, 1870.

(86) Kang, H. L.; Huang, G. L.; Ma, S. L.; Bai, Y. X.; Ma, H.; Li, Y. L.; Yang, X. J. J. Phys. Chem. C 2009, 113, 9157.

(87) Park, D. H.; Kim, J. E.; Oh, J. M.; Shul, Y. G.; Choy, J. H. J. Am. Chem. Soc. 2010, 132, 16735. 